LBNL-56756

\title{
Easing the Natural Gas Crisis: Reducing Natural Gas Prices through Increased Deployment of Renewable Energy and Energy Efficiency
}

\author{
Prepared for the \\ Office of Planning, Budget \& Analysis, and the \\ Wind \& Hydropower Technologies Program \\ Assistant Secretary for Energy Efficiency and Renewable Energy \\ U.S. Department of Energy
}

Principal Authors

Ryan Wiser, Mark Bolinger, Matt St. Clair

Ernest Orlando Lawrence Berkeley National Laboratory

1 Cyclotron Road, MS 90R4000

Berkeley CA 94720-8136

January 2005

The work described in this paper was funded by the Assistant Secretary of Energy Efficiency and Renewable Energy, Office of Planning, Budget \& Analysis and Wind \& Hydropower Technologies Program, of the U.S. Department of Energy under Contract No. DE-AC03-76SF00098. 



\section{Acknowledgments}

The work described in this report was funded by the Assistant Secretary of Energy Efficiency and Renewable Energy, Office of Planning, Budget \& Analysis and Wind \& Hydropower Technologies Program, of the U.S. Department of Energy under Contract No. DE-AC0376SF00098. We particularly appreciate the support and encouragement of Sam Baldwin, Mary Beth Zimmerman, Scott Hassell, and Jack Cadogan of the U.S. Department of Energy (DOE). For reviewing previous versions of this manuscript, we thank Steven Clemmer and Jeff Deyette (UCS), Christopher Namovicz and Alan Beamon (U.S. EIA), Anna Shipley and Neal Elliott (American Council for an Energy-Efficient Economy), Scott Hassell (U.S. DOE), Shimon Awerbuch (University of Sussex), and Nan Wishner (LBNL). For providing data, we appreciate the assistance of Jeff Deyette (UCS), Alison Bailie (Tellus), Christopher Namovicz (U.S. EIA), and Alex Lekov (LBNL). A special thanks to Kristina LaCommare of LBNL for her assistance with numerous NEMS runs, and for helping in the interpretation of the output of those runs. 



\section{Table of Contents}

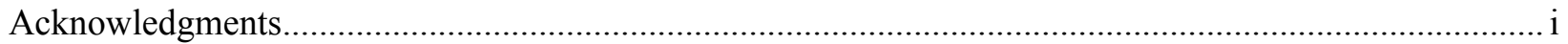

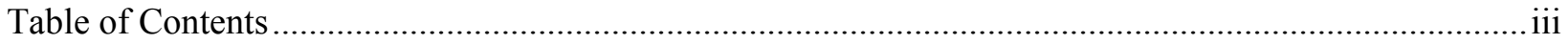

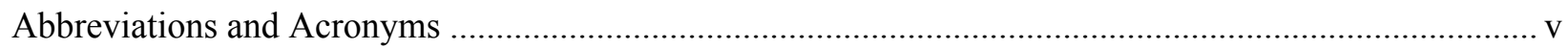

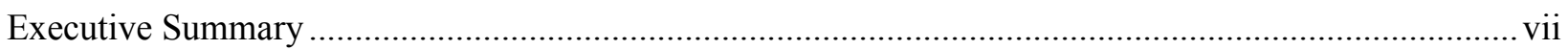

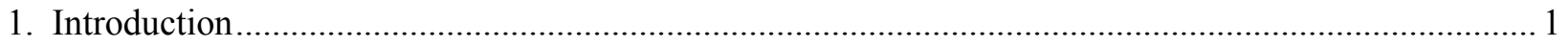

2. Natural Gas Supply and Demand: A Review of Economic Theory …............................................ 3

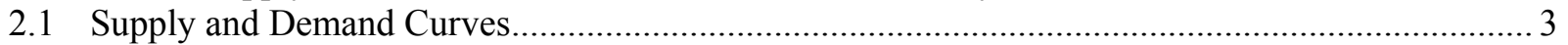

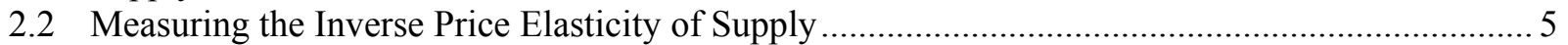

2.3 Social Benefits, Consumer Benefits, and Wealth Transfers ..................................................... 5

3. A Review of Previous Studies of the Impact of RE/EE on Gas Prices ............................................ 9

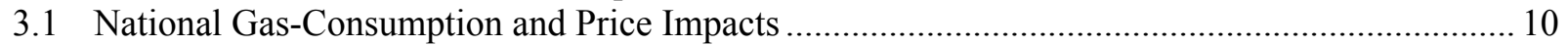

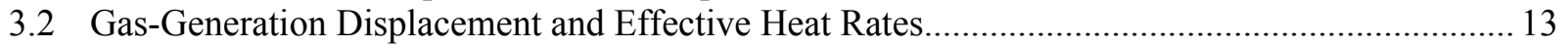

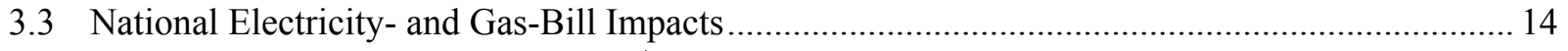

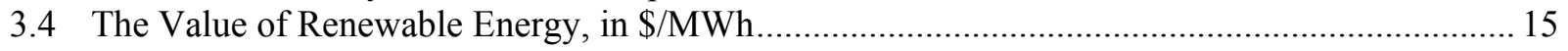

4. Summary of Implied Inverse Price Elasticities of Supply …..................................................... 17

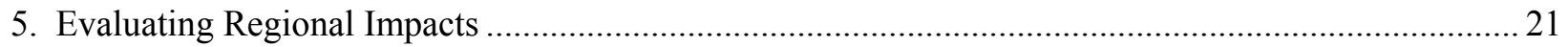

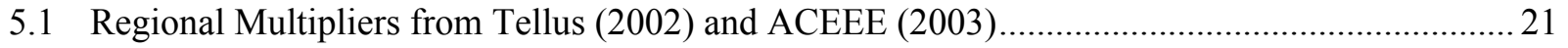

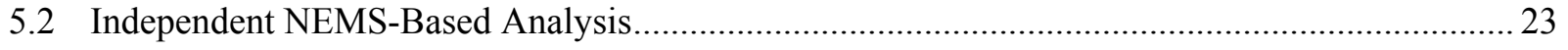

6. Benchmarking Against Other Markets and Energy Models ............................................................2 25

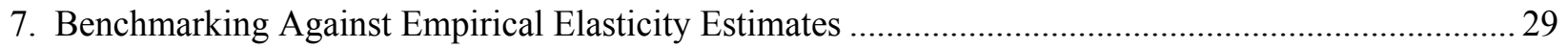

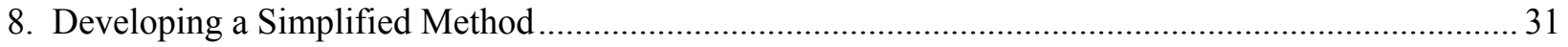

8.1 Why Develop a Simplified Tool to Analyze Gas-Price Impacts? ............................................... 31

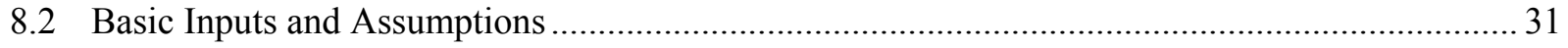

8.3 Applying the Simplified Analysis Tool to RE and EE Deployment Scenarios ........................... 33

8.3.1 Scenarios and Scenario-Specific Input Assumptions ......................................................... 33

8.3.2 Impact on National Average Delivered Gas Prices................................................... 35

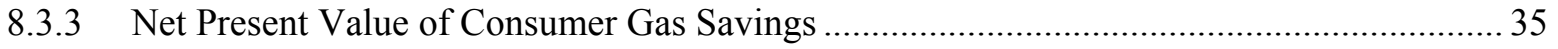

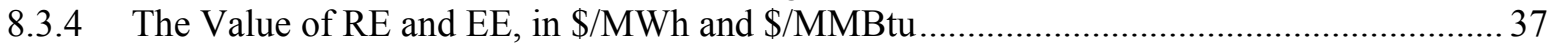

8.4 Calculating the Generic Consumer Value of RE and EE, in $\$ / \mathrm{MWh}$........................................ 38

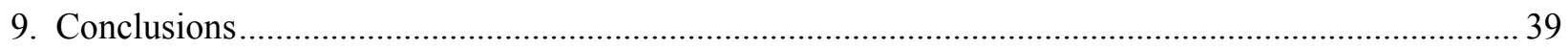

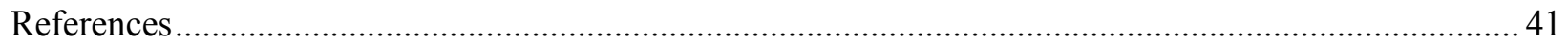

Appendix A. Impact of Incremental Renewable Energy Generation on Natural Gas Generation

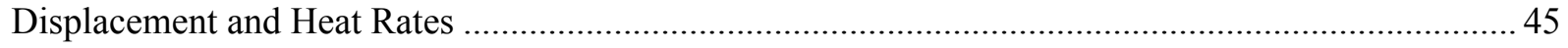





\section{Abbreviations and Acronyms}

$\begin{array}{ll}\text { ACEEE } & \text { American Council for an Energy-Efficient Economy } \\ \text { AEO } & \text { Annual Energy Outlook } \\ \text { AFUE } & \text { annual fuel utilization efficiency } \\ \text { AWEA } & \text { American Wind Energy Association } \\ \text { Bcf } & \text { billion cubic feet } \\ \text { Btu } & \text { British thermal unit } \\ \text { CRA } & \text { Charles River Associates } \\ \text { E2020 } & \text { Energy 2020 } \\ \text { EE } & \text { energy efficiency } \\ \text { EEA } & \text { Energy and Environmental Analysis, Inc. } \\ \text { EIA } & \text { Energy Information Administration } \\ \text { EMF } & \text { Energy Modeling Forum } \\ \text { GDP } & \text { gross domestic product } \\ \text { GWh } & \text { gigawatt hour } \\ \text { IPM } & \text { Integrated Planning Model } \\ \text { kWh } & \text { kilowatt hour } \\ \text { LNG } & \text { liquefied natural gas } \\ \text { MARKAL } & \text { MARKet ALlocation model } \\ \text { MMBtu } & \text { million BTU } \\ \text { MWh } & \text { megawatt hour } \\ \text { NANGAS } & \text { North American Natural Gas Analysis System } \\ \text { NARG } & \text { North American Regional Gas model } \\ \text { NARUC } & \text { National Association of Regulatory Utility Commissioners } \\ \text { NEMS } & \text { National Energy Modeling System } \\ \text { NPC } & \text { National Petroleum Council } \\ \text { NPV } & \text { net present value } \\ \text { OPEC } & \text { Organization of the Petroleum Exporting Countries } \\ \text { POEMS } & \text { Policy Office Electricity Modeling System } \\ \text { PSC } & \text { Public Service Commission } \\ \text { RE } & \text { renewable energy } \\ \text { RPS } & \text { renewable portfolio standard } \\ \text { UCS } & \text { Union of Concerned Scientists } \\ & \end{array}$





\section{Executive Summary}

Heightened natural gas prices have emerged as a key energy-policy challenge for at least the early part of the $21^{\text {st }}$ century. With the recent run-up in gas prices and the expected continuation of volatile and high prices in the near future, a growing number of voices are calling for increased diversification of energy supplies. Proponents of renewable energy and energy efficiency identify these clean energy sources as an important part of the solution.

Increased deployment of renewable energy (RE) and energy efficiency (EE) can hedge natural gas price risk in more than one way, but this paper touches on just one potential benefit: displacement of gas-fired electricity generation, which reduces natural gas demand and thus puts downward pressure on gas prices. Many recent modeling studies of increased RE and EE deployment have demonstrated that this "secondary" effect of lowering natural gas prices could be significant; as a result, this effect is increasingly cited as justification for policies promoting $\mathrm{RE}$ and EE.

This paper summarizes recent studies that have evaluated the gas-price-reduction effect of RE and EE deployment, analyzes the results of these studies in light of economic theory and other research, reviews the reasonableness of the effect as portrayed in modeling studies, and develops a simple tool that can be used to evaluate the impact of RE and EE on gas prices without relying on a complex national energy model. Key findings are summarized below.

\section{Review of Economic Theory on a Shifting Natural Gas Demand Curve}

- Economic theory predicts that increased RE and/or EE deployment can reduce natural gas prices. Economic theory predicts that increased RE and EE will lead to an inward shift in the natural gas demand curve, leading to a reduction in natural gas prices. These reductions in gas prices benefit consumers by reducing fuel costs faced by electricity generators and by reducing the price of natural gas delivered for direct use in the residential, commercial, industrial, and transportation sectors. The magnitude of the price reduction will vary based on a number of factors, including the degree of natural gas displacement with increased RE and EE deployment, and the shape of the natural gas supply curve (measured by the inverse price elasticity of natural gas supply). The reduction is likely to be more significant in the near term than in the longer term.

- The contribution of RE and EE to lowering gas prices may in part be a gain to natural gas consumers that comes at the expense of gas producers. According to standard economic theory, lower natural gas prices that result from an inward shift in the demand curve may not lead to a gain in net economic welfare but rather represent a shift of resources from natural gas producers to natural gas consumers. Wealth transfers of this type are not a primary justification for policy intervention on economic grounds. Nonetheless, if policymakers are concerned about the impact of gas prices on consumers or are concerned about the macroeconomic impacts of higher gas prices, ${ }^{1}$ then policies to reduce gas demand

\footnotetext{
${ }^{1}$ For example, partly in response to recent high natural gas prices, fertilizer manufacturing has shifted overseas, while fertilizer prices have increased. At the same time, recognition of domestic supply constraints is leading to a realization that foreign liquefied natural gas (LNG) will become a large part of the U.S. gas supply picture.
} 
might be considered appropriate; at a minimum, policymakers might view reduced gas prices as a positive secondary effect of increased RE and EE deployment.

\section{Review of Previous Renewable Energy and Energy Efficiency Studies}

- Previous modeling studies consistently find that increased levels of RE and EE will put downward pressure on natural gas prices. We review five studies by the Energy Information Administration (EIA), six by the Union of Concerned Scientists (UCS), one by the Tellus Institute, and one by the American Council for an Energy-Efficient Economy (ACEEE). Several of these studies conduct multiple analyses, and all except the ACEEE study use the EIA's National Energy Modeling System (NEMS). The ACEEE study uses a model developed by Energy and Environmental Analysis, Inc., and - unlike the other studies reviewed here - focuses on the ability of RE and EE investments to reduce gas prices in the short term. ${ }^{2}$ Most of the studies that we review evaluate national renewable portfolio standard (RPS) proposals, though some evaluate state RPS policies and others also include EE. These studies consistently find that RE and EE deployment will reduce natural gas demand, thereby putting downward pressure on gas prices (see Figure ES-1).

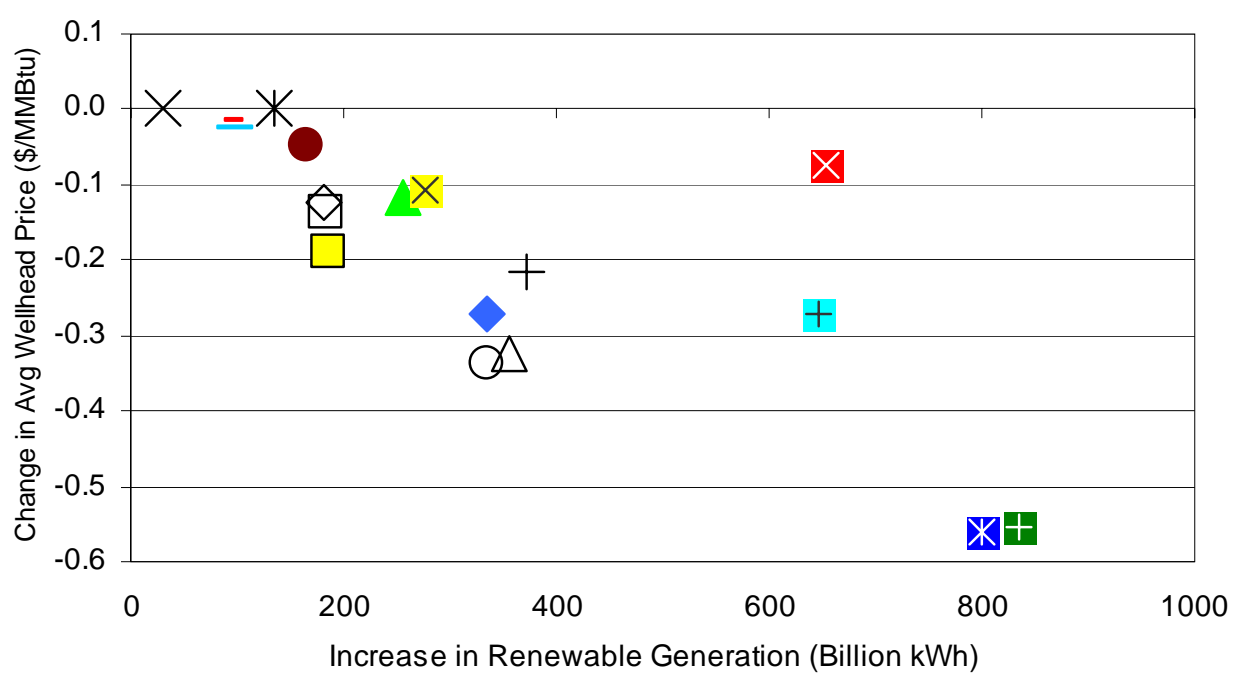

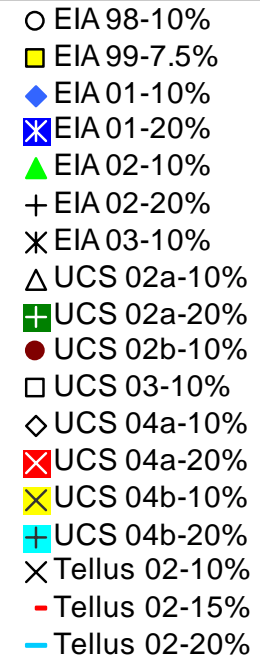

Figure ES-1. Forecasted Natural Gas Wellhead Price Reduction in 2020

- Variations in the magnitude of the gas price reductions among studies are significant. Even when we control for the fact that the studies evaluate different levels of RE and EE penetration, we observe that the studies find different levels of gas displacement resulting from increased RE and EE deployment. This difference is influenced by the relative assumed cost of coal and gas - i.e., the higher gas-price forecasts of recent years suggest that coal may out-compete gas for new generation additions, and therefore RE and EE may increasingly displace coal (rather than gas). We also observe that the studies implicitly assume different

\footnotetext{
${ }^{2}$ Though most of the results presented in this paper derive from a single energy model (NEMS), we benchmark these results against other commonly used energy models and against an historical literature that reviews the supply elasticity of energy commodities. These comparisons allow greater confidence in our results.
} 
shapes for the natural gas supply curve (and therefore different implicit inverse price elasticities of supply); these variations in results are not always within reasonable bounds.

- Despite the above variations, studies generally show that each $1 \%$ reduction in national gas demand is likely to lead to a long-term (effectively permanent) average reduction in wellhead gas prices of $\mathbf{0 . 8 \%}$ to $\mathbf{2 \%}$. Although there are some outliers, 13 of 19 analyses are consistent with this finding. Some studies predict even larger impacts, especially in the near term. Reductions in wellhead prices will reduce wholesale and retail electricity rates and will also reduce residential, commercial, and industrial gas bills.

- Natural gas bill savings for consumers are predicted to be sizable. For studies that evaluate national RPS proposals (typically $10 \%$ or $20 \% \mathrm{RE}$ ), the net present value (NPV) of national, natural gas bill savings from 2003-2020 reaches as high as \$74 billion; nine of fifteen analyses are within the range of $\$ 10$ to $\$ 40$ billion.

- The consumer gas bill savings associated with increased RE and EE, expressed in terms of \$ per MWh of renewable energy, are generally estimated at between $\$ 7.50 / \mathrm{MWh}$ and $\mathbf{\$ 2 0} / \mathbf{M W h}$. Considering the predicted reduction in consumer gas bills as well as an assumed one-for-one pass-through to consumers of reductions in electricity-sector gas costs, Figure ES-2 shows, by study, the range of consumer benefits delivered from increased RE generation, expressed in terms of \$ per MWh of renewable energy. Results suggest that each megawatt hour (MWh) of incremental RE and EE provides, on average, national consumer benefits in the form of gas savings that range from $\$ 6 / \mathrm{MWh}$ to $\$ 35 / \mathrm{MWh}$, with a general trend toward savings between $\$ 7.50$ and $\$ 20 / \mathrm{MWh}$.

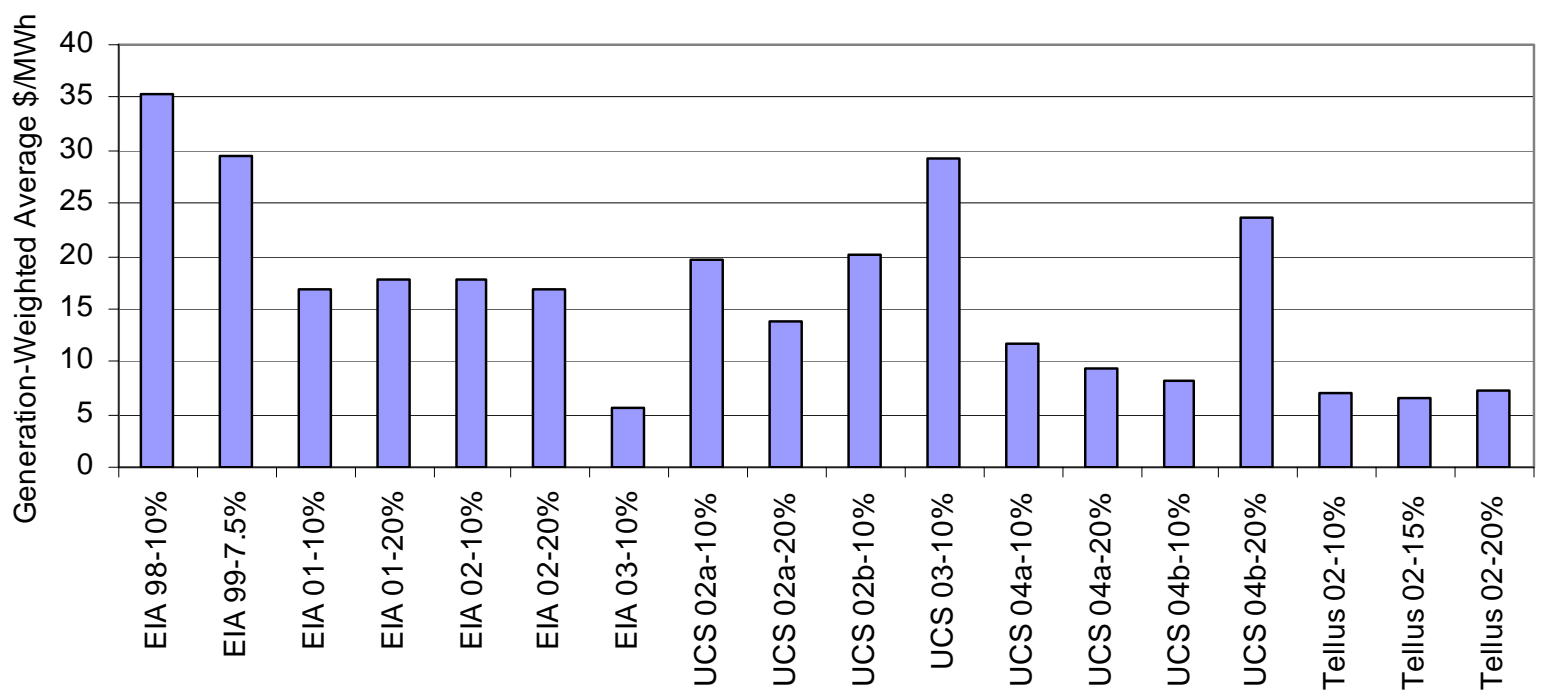

Figure ES-2. Consumer Gas-Savings Benefits of Increased RE Production (in \$/MWh)

- Regional gas price impacts of regionally targeted RE and EE may be more sizable than the national impacts of these regionally targeted investments, but the regional consumer savings on an aggregate dollar (or on a dollar per MWh of renewable energy) basis are more modest. Findings from our own NEMS-based analysis, as well as a review of other 
studies, suggest that the gas-price impacts of regionally focused RE and EE investments are likely to be magnified (relative to the national gas-price impacts) in the region where those investments take place, due to an assumed near-term alleviation of gas transportation constraints. That said, the regional aggregate gas bill savings from regionally targeted RE and EE investments are likely to be far more modest than the national impacts of those investments. The relatively modest savings are because the regional gas-price reduction applies to a much lower (i.e., regional instead of national) volume of gas consumption, so the aggregate dollar savings are smaller.

- Findings from the studies that we surveyed are somewhat consistent with those of other national energy models and with empirical elasticity estimates from the economics literature; nonetheless, more research is warranted. The results of the studies reviewed in this paper, most of which rely on NEMS, appear largely consistent with those of other related work. Nonetheless, many uncertainties remain, and we strongly recommend increased research to more completely validate these findings. In the meantime, when estimating the impact of RE and EE on natural gas prices, it is preferable to consider a range of assumptions that describe the boundaries of the possible effects rather than relying on the results of any single modeling run.

\section{Developing and Using a Simplified Analysis Tool to Evaluate RE and EE Impacts}

- Based on our findings, we have developed a simple, transparent analysis tool for evaluating the potential impact of RE and EE investments on natural gas prices and bill savings. Many organizations that evaluate RE and EE investments and policies do not have the capability to run complex, integrated energy models, so these organizations rely on simple, transparent tools that cannot account for secondary natural gas effects. National energy models also generally cannot flexibly account for uncertainties in the level of impact expected from increased RE and $\mathrm{EE}$ investments. This paper describes an Excel-based analysis tool that overcomes these challenges. We use the tool to evaluate a range of $\mathrm{RE}$ and EE scenarios, including those listed in Text Box ES-1.

- In developing and using this simplified analysis tool, we rely on

\section{Text Box ES-1:}

Scenarios Evaluated with Simplified Analysis Tool

- Existing State RPS Policies: the expected impact of the existing 18 state RPS policies

- The California RPS: the expected impact of the California RPS (20\% RE by 2010)

- New England RPS Policies: the expected impact of three existing New England RPS policies

- The Newly Established New York RPS: the expected impact of the New York RPS (25\% RE by 2013)

- State Fund Support for RE Projects: the potential impact of state fund support for large-scale RE projects already on line (707 MW) or that have been obligated funds (1,550 MW)

- Projections from the American Wind Energy Association (AWEA) of the Near-Term Growth of Wind Capacity: 15,000 MW of wind installed by 2009, with AWEA-derived gas displacement assumptions

- Aggressive Solar Energy Industries Association (SEIA) Goal of 36 gigawatts (GW) of solar by 2020: based on SEIA's 2004 roadmap

- California Natural Gas Efficiency Goals: savings goals from the California Public Utilities Commission, 44,400,000 MMBtu by 2013

- Two Possible National Residential Furnace and Boiler Efficiency Standards: annual savings by 2035 equal $108,300,000$ MMBtu and 376,100,000 MMBtu in the two scenarios 
basic assumptions that are intended to be consistent with those from recent national energy models. These assumptions include: 1) a $40 \%$ natural gas displacement ratio (each MWh of renewable energy is assumed to displace $0.4 \mathrm{MWh}$ of natural gas generation); 2) heat rates for displaced gas-fired generation that drop from 9,000 British thermal units per kilowatt hour (Btu/kWh) to 7,500 Btu/kWh over time; 3) base-case gas consumption and wellhead prices from EIA's Annual Energy Outlook (AEO) 2004; 4) a one-for-one wellheadto-delivered gas price reduction; 5) inverse price elasticities of gas supply of $0.8,1.2$, and 2.0 , consistent with the central range from the studies reviewed in this paper (meaning that each $1 \%$ reduction in national gas demand results in a $0.8 \%$ to $2 \%$ reduction in wellhead gas prices); and, 6) where regional analysis is performed, and to reflect regional gas transportation constraints, a regional delivered gas price multiplier of three in the first year, dropping linearly over time to one by year 20. See Section 8 for a more detailed explanation of these and other scenario-specific assumptions. The range of results provided for each scenario simply reflects differences in the assumed inverse price elasticity of gas supply. The plausible range of impacts is greater than this, given uncertainties in gas displacement and other factors.

- The NPV of national consumer gas savings from the EE and RE scenarios that we evaluate can be significant (Figure ES-3). On a national basis, the NPV of consumer gas savings (through 2025 for all scenarios except the furnace standards, which are through 2035; $7 \%$ real discount rate) ranges from a low of $\$ 0.6$ billion to a high of $\$ 23$ billion. Scenarios that involve the largest amount of RE and EE deployment, combined with high levels of gas displacement, are those with the largest impacts. For those scenarios that involve regionally targeted RE and EE investment, Figure ES-4 shows that the regional gas bill impacts are far more modest than the national impacts of those same investments. Regionally targeted RE and $\mathrm{EE}$ investments have a differentially large impact on regional (versus national) gas prices, but the resulting total regional gas bill savings are smaller than the total national savings because the regional gas price savings apply to the more limited regional (versus national) gas consumption.

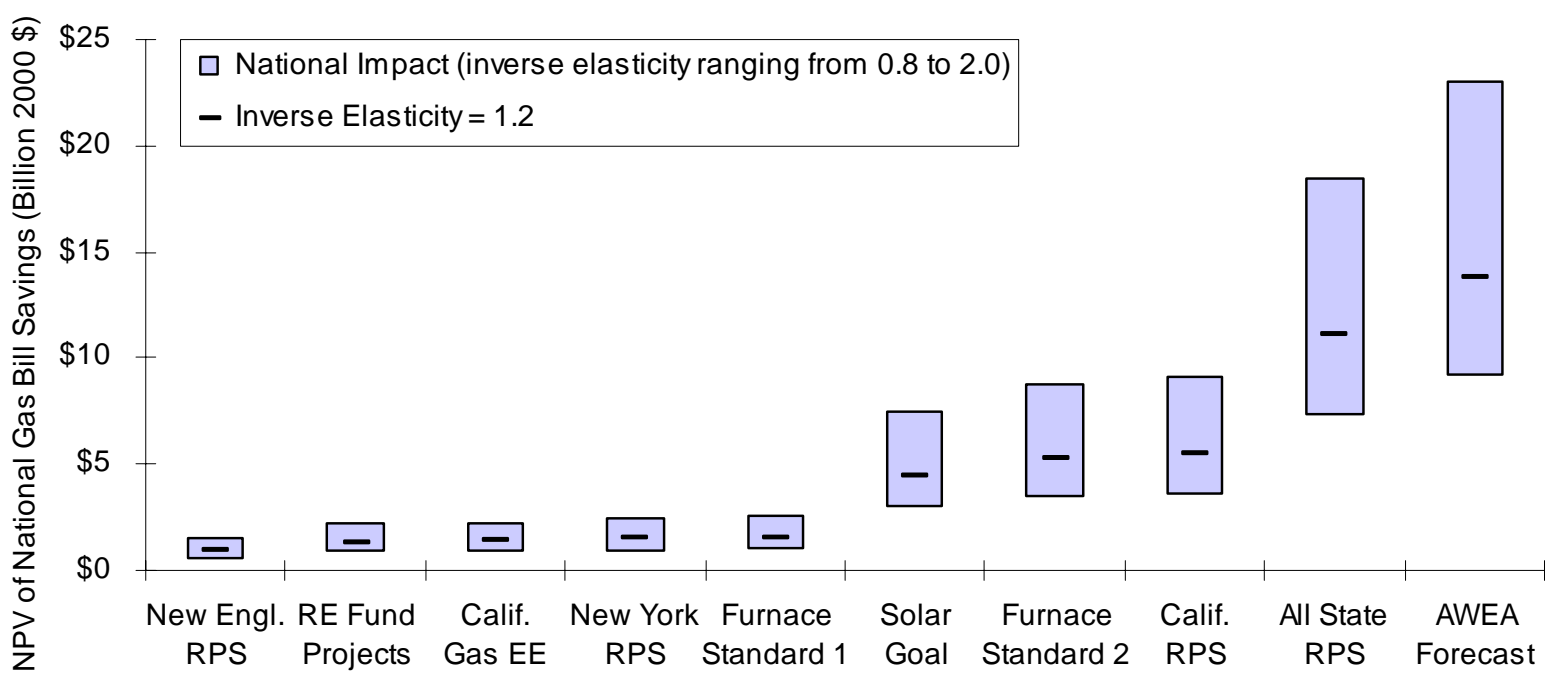

Figure ES-3. NPV of Consumer Gas Savings (national impacts) 


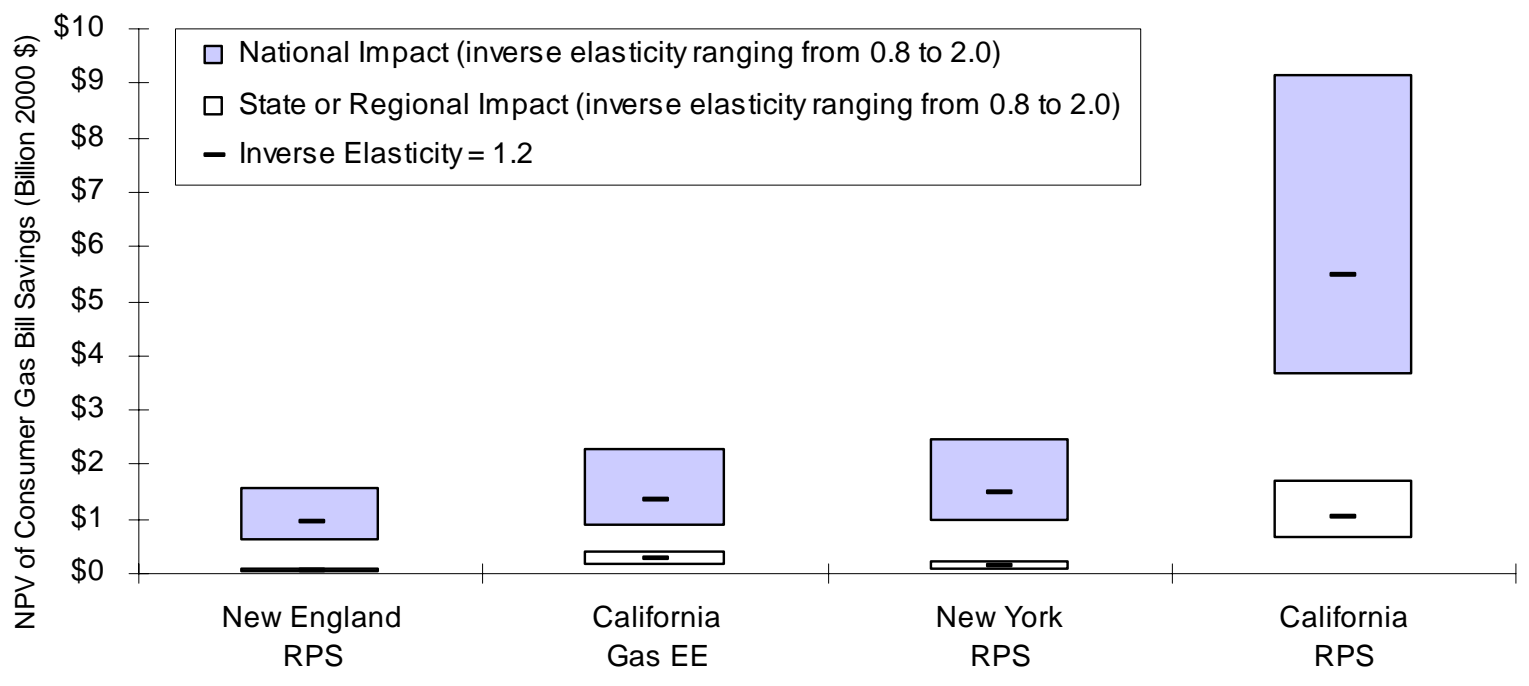

Figure ES-4. NPV of Consumer Gas Savings (national and regional impacts)

- The consumer gas savings associated with RE and EE, expressed in terms of \$ per MWh of RE, or \$ per million-BTU (MMBtu) of gas savings, may also be substantial. Applying the aggregate annual gas bill savings to the incremental amount of RE and/or EE in each scenario, we can estimate the average consumer benefits of increased RE or electricity $\mathrm{EE}$ (in \$/MWh) or gas EE (in \$/MMBtu). Figure ES-5 shows the results, on both a national and a state/regional basis. At a national level, we find that increased RE (wherever located) can benefit consumers to the tune of approximately $\$ 10$ to $\$ 65$ per MWh (in the case of increased RE scenarios), or $\$ 3$ to $\$ 9$ per MMBtu (in the case of the three gas efficiency scenarios). These results, like those mentioned previously, suggest that the national consumer gas-price benefits from RE and EE may well be substantial. On a regional basis, the benefits are more modest, with a high of $\sim \$ 5 / \mathrm{MWh}$ (for the regional RE scenarios), or $\$ 1 / \mathrm{MMBtu}$ (for the California gas efficiency scenario). Again, this reflects the fact that although the regional gas price will tend to fall more than the national price, this regional gas-price reduction applies to a much lower (i.e., regional instead of national) volume of gas consumption. We conclude that if the effect of RE and EE on consumer gas savings is to play a role in policy debates, it is more likely to play that role in national, rather than state or regional, discussions. 


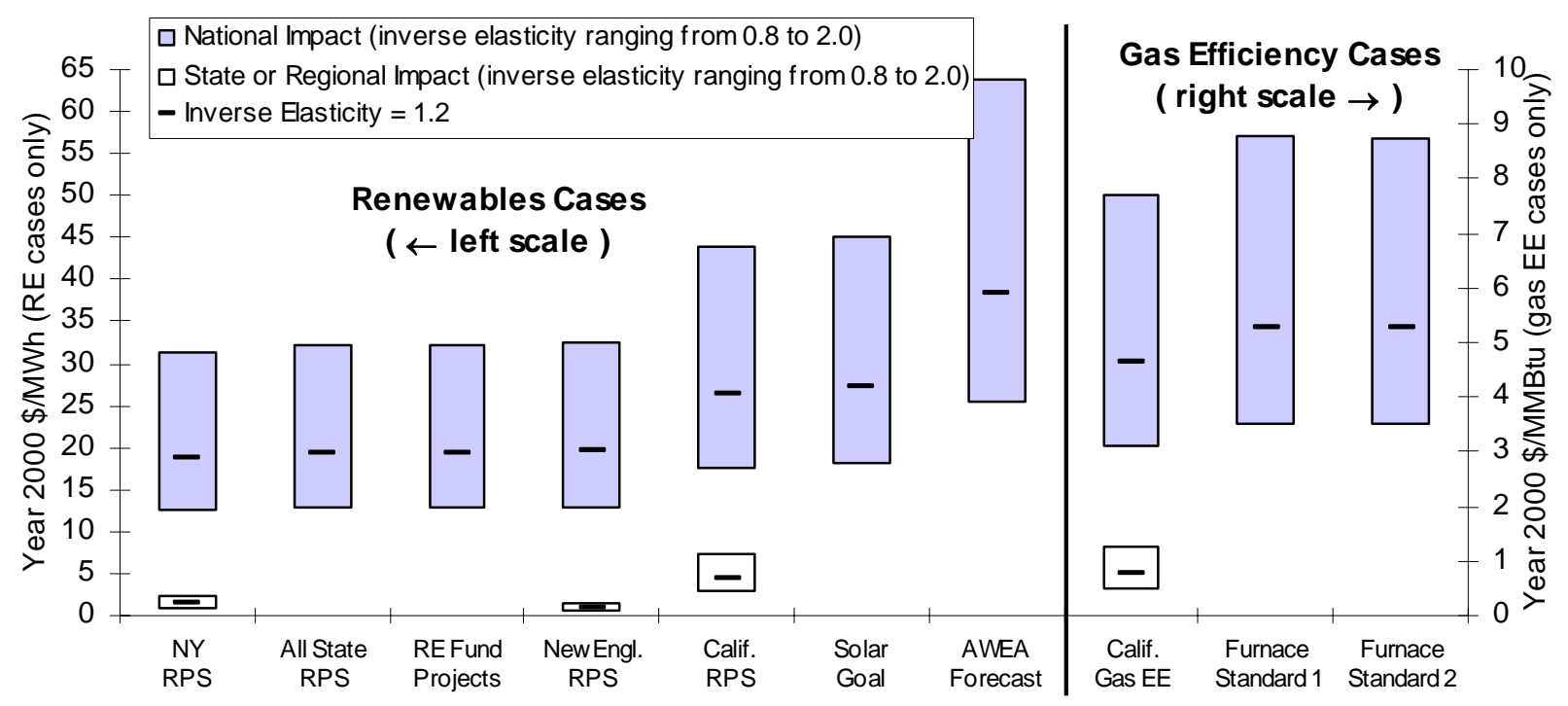

Figure ES-5. Average Consumer Gas-Savings Benefits of RE and EE (in \$/MWh or \$/MMBtu) 



\section{Introduction}

Renewable energy (RE) and energy efficiency (EE) have historically been supported because of their perceived economic, environmental, economic-development, and national-security benefits. Recently, extreme price volatility in wholesale electricity and natural gas markets has led to discussions about the potential risk mitigation value of these clean energy resources. Deepening concerns about the ability of conventional North American gas production to keep up with demand have also resulted in a growing number of voices calling for resource diversification (see, e.g., Bernstein, Holtberg, \& Ortiz 2002; Henning, Sloan \& de Leon 2003; NARUC 2003; NPC 2003a).

$\mathrm{RE}$ and $\mathrm{EE}$ are a direct hedge against volatile and escalating gas prices because they reduce the need to purchase variable-price natural gas-fired electricity generation, replacing that generation with fixed-price RE or EE resources (see, e.g., Bolinger, Wiser, \& Golove 2003; Awerbuch 2003). In addition to this direct contribution to price stability, by displacing marginal gas-fired generation, RE and EE can reduce demand for natural gas and thus indirectly place downward pressure on gas prices. ${ }^{3}$

Many recent modeling studies of increased RE and EE deployment have demonstrated that this "secondary" effect of putting downward pressure on natural gas prices could be significant, with the consumer benefits from reduced gas prices in many cases more than offsetting any increase in electricity costs caused by RE and/or EE deployment. As a result, this price effect is increasingly cited as justification for policies promoting RE and EE. Yet, to date, little work has focused on reviewing the reasonableness of this effect as it is portrayed in various studies, nor have studies attempted to benchmark that output against economic theory. This paper is a first attempt to address these two issues.

The remainder of the paper is organized as follows:

- Section 2 reviews economic theory to explain the principles underlying the pricesuppression effect. We describe short- and long-term price dynamics in the natural gas market, introduce the inverse price elasticity of gas supply, and discuss the nature of the benefit derived from a reduction in natural gas demand and prices.

- Section 3 examines many of the modeling studies conducted during the past five years that have measured the price-reduction effect, illustrating the potential impacts of RE and EE deployment on natural gas demand and wellhead prices and on consumer electricity and gas bills. We also calculate the effective $\$$ MWh value of increased RE and EE investments that is a result of the impact of those investments on gas prices.

- Section 4 calculates the long-term inverse price elasticity of natural gas supply implied by the modeling output of each study that we review. This allows us to compare and assess the consistency of the national natural gas price response described in the studies.

- Section 5 reviews the few studies that have assessed differential regional impacts of RE and EE deployment. Most of the studies summarized in this paper focus on national-level impacts, but differential regional impacts might be expected because of pipeline

\footnotetext{
${ }^{3}$ End-use natural gas efficiency measures as well as improvements in natural gas conversion efficiency would also directly reduce gas demand.
} 
transportation constraints. Because there are so few regional studies, we also conduct our own analysis of regional impacts using the National Energy Modeling System (NEMS).

- Section 6 compares the range of inverse price elasticities from Section 4 with results from other analyses using NEMS (to test for intra-model consistency) and with other energy models altogether (to test for inter-model consistency). This analysis allows us to begin to assess the reasonableness of the national-level impacts described in Section 4.

- Section 7 compares the inverse price elasticities from Section 4 with the limited empirical economics literature that estimates the historical elasticities for natural gas and other energy commodities (to test for model consistency with the real world). This allows us to further assess the reasonableness of the impacts of RE and EE predicted by the modeling studies we reviewed.

- Section 8 describes a simple, transparent, flexible method for evaluating the potential impact of RE and EE investments on natural gas prices and bill savings. We developed this model to offer an alternative to resource-intensive, non-transparent integrated national energy models. Our method requires only a simple Excel spreadsheet. We apply our simplified method to estimate the potential beneficial impact on gas prices and bills of a number of RE and EE deployment programs.

- Section 9 summarizes our key findings. ${ }^{4}$

\footnotetext{
${ }^{4}$ Although this paper emphasizes the impact of RE and EE on natural gas prices, similar effects would result from increased utilization of other non-gas energy sources (e.g., coal or nuclear power).
} 


\section{Natural Gas Supply and Demand: A Review of Economic Theory}

The subsections below review the economic concepts of supply and demand curves as they relate to natural gas, introduce the inverse price elasticity of natural gas supply, and discuss the nature of the benefit derived from a reduction in natural gas demand and prices.

\subsection{Supply and Demand Curves}

It is not clear whether today's inflated natural gas prices represent merely a short-term imbalance between supply and demand or a longer-term effect that reflects the true marginal cost of production (see, e.g., EMF 2003; Henning, Sloan \& de Leon 2003; Holtberg 2002; NPC 2003a). ${ }^{5}$ In either case, economic theory predicts that a reduction in natural gas demand, whether caused by enhanced electricity or natural gas efficiency or by increased deployment of RE, will generally lead to a reduction in the price of natural gas relative to the price that would have been expected under higher-demand conditions. ${ }^{6}$

As shown in Figure 1, this price reduction $\left(\mathrm{P}_{0} \rightarrow \mathrm{P}_{1}\right)$ results from an inward shift in the aggregate demand curve for natural gas $\left(\mathrm{Q}_{0} \rightarrow \mathrm{Q}_{1}\right){ }^{7}$ Because gas consumers are "price takers" in a market in which price is determined by national supply and demand conditions (with some regional differentiation), the price reduction benefits consumers by reducing gas prices for electricity

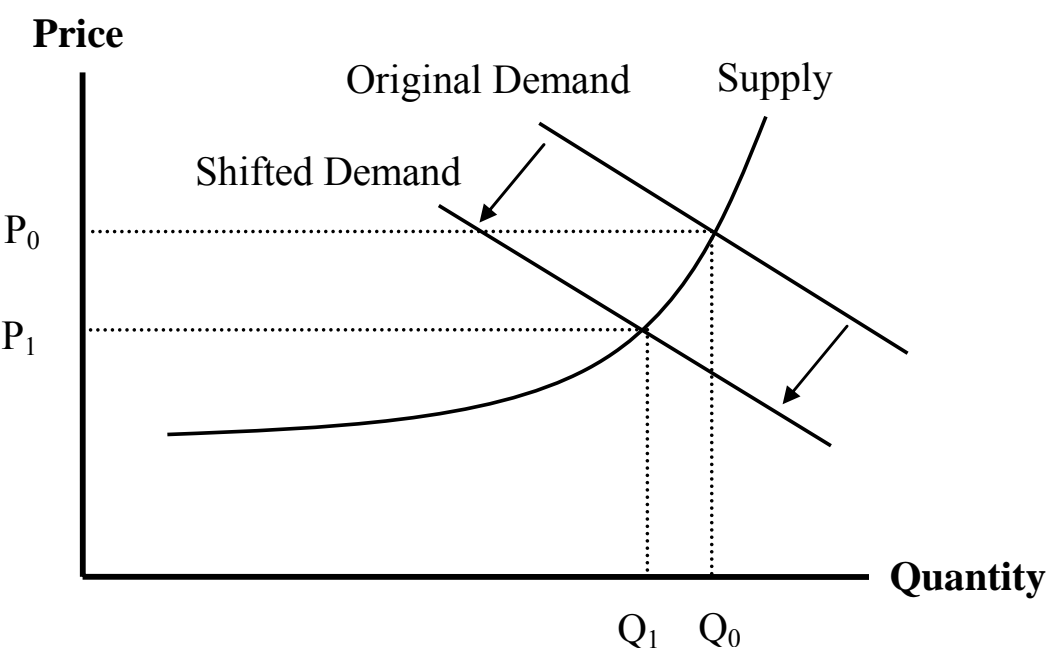

Figure 1. The Effects of a Shift in Demand for Natural Gas generators (assumed to be passed through in the form of lower electricity prices), and by reducing the prices of gas delivered for direct use in the residential, commercial, industrial, and transportation sectors.

The magnitude of the price reduction will depend on the amount of demand reduction: greater displacement of demand for gas will lead to greater drops in the price of the commodity. ${ }^{8}$ As

\footnotetext{
${ }^{5}$ This uncertainty is reflected in the large range of prices in recent forecasts (see, e.g., EMF 2003).

${ }^{6}$ It is worthy of note that natural gas prices may fall over time even with increasing demand if technological progress allows gas to be extracted at lower prices despite the need to extract resources from increasingly less attractive resource areas. Our argument here is simply that a reduction in natural gas demand is expected, all else being equal, to result in lower natural gas prices than would be seen under a higher-demand scenario.

${ }^{7}$ Aggregate demand for gas includes electricity-sector demand as well as direct residential-, commercial-, industrial-, and transportation-sector demands.

${ }^{8}$ We would not generally expect any particular threshold of demand reduction to be required to lower the price of gas (unless the supply curve was flat over some of its range). Instead, greater quantities of gas savings should simply
} 
long as gas prices remain within reasonable bounds, $\mathrm{RE}$ and $\mathrm{EE}$ are expected to displace a large amount of gas generation; the higher gas-price forecasts of recent years, however, suggest that coal may out-compete gas for new generation additions, and therefore RE and EE may increasingly displace coal (rather than gas), muting the impact on gas prices.

Equally important, the shape of the natural gas supply curve - i.e., the relationship between the level of natural gas production and the price of supply - will also have a sizable impact on the magnitude of the price reduction. ${ }^{9}$ The shape of the supply curve for natural gas will, in turn, depend on whether one considers short-term or long-term effects. Economists generally assume upward, steeply sloping supply curves in the short term when supply constraints exist in the form of fixed inputs like labor, machinery, and well capacity. In this instance, gas producers are unable or unlikely to quickly and dramatically increase (or decrease) supply in response to higher (or lower) gas prices (Henning, Sloan \& de Leon 2003). In the long term, the supply curve will presumably flatten because supply will have time to adjust to higher (or lower) demand expectations, for example, in the form of increased (or decreased) exploration and drilling expenditures (Dahl \& Duggan 1998).

Because natural gas is a non-renewable commodity, the long-term supply curve must eventually slope upward as the least-expensive resources are exhausted. If the pace of technological innovation in exploration and extraction is rapid, however, the transition to more expensive reserves may be delayed, and the long-term supply curve may remain relatively flat. The shape of the long-term supply curve is an empirical question and is subject to great uncertainty and debate. Nonetheless, economists generally agree that, although both the short- and long-term supply curves slope upward, the long-term supply curve will generally be flatter than the shortterm supply curve. This implies that the impact of increased RE and EE deployment on natural gas prices will be greater in the short term than in the long term. ${ }^{10}$ We return to these issues later when we review modeling output.

In this paper, we primarily emphasize the long-term impacts of RE and EE investments and thus focus most of our attention on the shape of the long-term supply curve. We take this approach for two key reasons. First, RE and EE investments are typically long term in nature, so their most enduring effects are likely to occur over the long term. Second, the model results presented in this paper often do not clearly distinguish between short-term and long-term effects, and most models appear better suited to long-term analysis. ${ }^{11}$

Much of this paper focuses on the national impacts of increased RE and EE deployment. However, the shape of the supply curve for delivered natural gas may vary by region because of

result in higher levels of price reduction. The impact on prices, however, need not be linear over the full range of demand reductions; it will, instead, depend on the exact - as yet unknown - shape of the supply curve in the region in which it intersects the demand curve.

${ }^{9}$ We assume that the short-term supply curve (which is dependent on technology and the labor market) does not shift in response to a demand shock.

${ }^{10}$ Note that the long-term demand curve is also expected to be flatter than the short-term demand curve (EMF 2003). This too will moderate the long-term impacts of RE and EE investments on natural gas prices.

${ }^{11}$ In the case of NEMS, for example, reductions in gas demand do not appear to have a differentially large national impact on natural gas prices in the short term; instead, short-term and long-term effects are similar in national RPS runs. 
regional variations in supply sources and transportation infrastructure. In particular, where transportation infrastructure is constrained, the short-term supply curve is expected to slope steeply upwards. Because we focus primarily on the impacts of RE and EE on national gas prices, these regional details are effectively summed into the national effects reported in this paper. In Section 5, however, we describe the limited results available on the regional impacts of regionally targeted $\mathrm{RE}$ and $\mathrm{EE}$ investments, and we incorporate a regional-impacts capability into the simplified analysis tool described in Section 8.

\subsection{Measuring the Inverse Price Elasticity of Supply}

It is convenient to use elasticity measures to estimate the degree to which shifts in natural gas demand affect the price of natural gas. The price elasticity of natural gas supply is a measure of the responsiveness of natural gas supply to the price of the commodity at a specific point on the supply curve. Price elasticity is calculated by dividing the percentage change in quantity supplied by the percentage change in price:

$\mathrm{E}=(\% \Delta \mathrm{Q}) /(\% \Delta \mathrm{P})$,

where $\mathrm{Q}$ and $\mathrm{P}$ denote quantity and price, respectively.

In the case of induced shifts in demand for natural gas, however, we are interested in understanding the change in price that will result from a given change in quantity, or the inverse price elasticity of supply ("inverse elasticity"):

$\mathrm{E}^{-1}=(\% \Delta \mathrm{P}) /(\% \Delta \mathrm{Q})$

Given greater supply responsiveness over the long term than in the short term, the long-term supply curve should exhibit lower inverse price elasticities of supply than will the short-term supply curve.

\subsection{Social Benefits, Consumer Benefits, and Wealth Transfers}

We have made the case that increased deployment of RE and EE can and should lower the price of natural gas relative to a business-as-usual trajectory. The magnitude of the expected price reduction is an empirical question that we address in later sections of this paper. Before proceeding, however, it is important to address the nature of the "benefit" obtained from the price reduction, because mischaracterizations of this benefit are common and may lead to unrealistic expectations and policy prescriptions.

In particular, according to economic theory, lower natural gas prices that result from an inward shift in the demand curve do not necessarily lead to a net gain in economic welfare, but rather to a shift of resources (i.e., a transfer payment) from natural gas producers to natural gas consumers. As natural gas producers see their profit margins decline (a loss of producer surplus), natural gas consumers benefit through lower gas bills (a gain of consumer surplus). Assuming a perfectly competitive and well-functioning aggregate economy, the net effect on aggregate social welfare (producer plus consumer surplus) is zero. Wealth transfers of this type are not a standard, primary justification for policy intervention on economic grounds. 
This effect is shown graphically in Figures 2 and 3. Figure 2 shows consumer and producer surplus before the demand shift, and Figure 3 shows the impact of the demand shift on consumer and producer surplus. After the shift, the market price and quantity of natural gas fall to $\mathrm{P}_{1}$ and $\mathrm{Q}_{1}$, respectively, and consumer surplus changes to include the cross-hatched area in Figure 3 that was previously producer surplus. This cross-hatched area represents the price-reduction benefit that consumers gain, and the redistribution of wealth from producers to consumers.

Reducing gas prices may still be of importance in policy circles, however, where it may be viewed as a positive ancillary effect of RE and/or EE deployment. Energy programs are frequently assessed using consumer impacts as a key metric. Furthermore, the wealth redistribution effect may, in fact, result in a social welfare gain if economy-wide macroeconomic adjustment costs are expected to be severe in the case of natural gas price spikes and escalation. Such

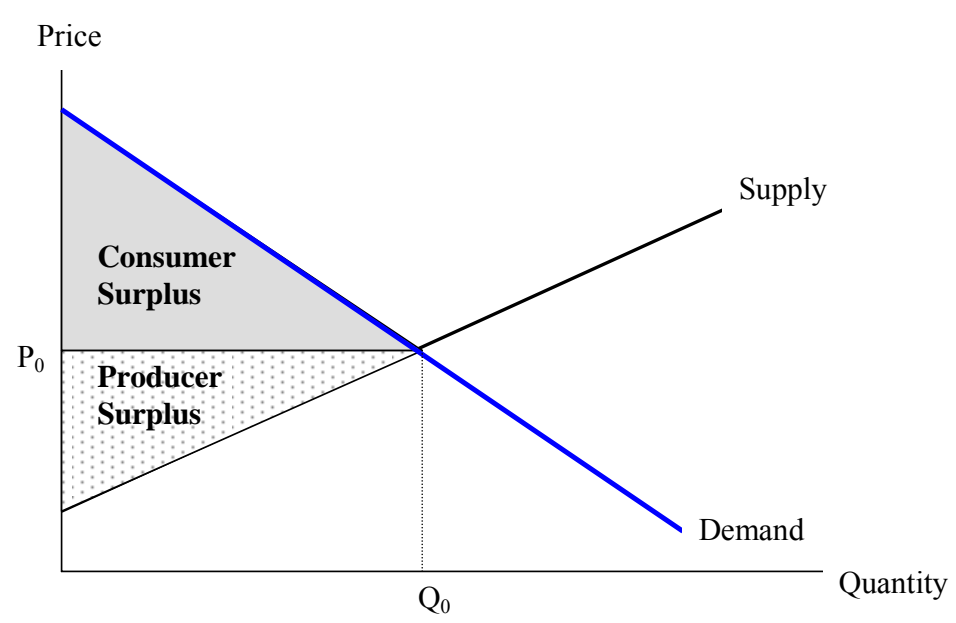

Figure 2. Consumer and Producer Surplus

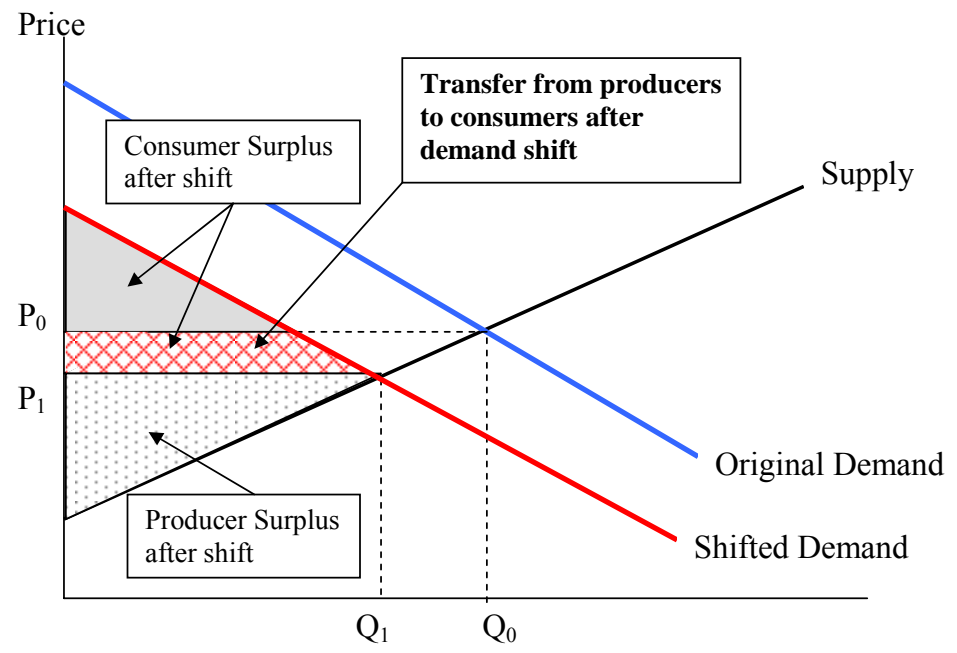

Figure 3. The Effect of a Demand Shift adjustment costs have been found to be significant in the case of oil price shocks and one might expect to discover a similar effect for natural gas, though research has not yet targeted this issue. ${ }^{12}$ Additionally, if consumers are located within the U.S. and producers are located outside of the U.S., the wealth redistribution would increase aggregate U.S. welfare, an increasingly likely situation as the country becomes more reliant on imports of natural gas [especially liquefied natural gas (LNG)]. ${ }^{13}$ Similarly, for state or regional analysis, if gas producers are

\footnotetext{
${ }^{12}$ Although the literature on the macroeconomic impacts of oil-price escalation is broad, we are aware of no research that has explored the impact of natural gas price escalation. Extrapolating from studies that have looked at oil-price shocks, Brown (2003) estimates that a sustained doubling of natural gas prices might reduce U.S. gross domestic product (GDP) by $0.6-2.1 \%$ below what it otherwise would be.

${ }^{13}$ See Parry \& Darmstadter (2003) for a recent summary of the literature on the costs of oil dependency, including macroeconomic adjustment costs and inter-country transfers.
} 
located out of state, the wealth redistribution would benefit the local region. ${ }^{14}$ Finally, lower natural gas prices may help preserve U.S. manufacturing jobs, ${ }^{15}$ lead to displacement of morepolluting energy sources, and reduce the cost of environmental regulatory compliance. Given these considerations, we believe that a case can be made for considering the gas-price effects of increased RE and EE in policy evaluation, though we leave it to others to further debate this point.

\footnotetext{
${ }^{14}$ Note that these statements about inter-country and inter-regional wealth transfers ignore the fact that the producers' stockholders may not be located in the same country or region in which the production takes place.

${ }^{15}$ For example, partly in response to recent high natural gas prices, fertilizer manufacturing has shifted overseas, while fertilizer prices have increased (EEA 2004).
} 



\section{A Review of Previous Studies of the Impact of RE/EE on Gas Prices}

Previous studies of RE and EE policies have estimated the impact of increased deployment of these resources on natural gas prices. Many of these studies have exclusively evaluated a renewables portfolio standard (RPS) - a policy that requires electricity suppliers to source an increasing percentage of their supply from RE over time; other studies have looked at EE and environmental policies. In most cases national-level policies have been the focus of attention, but state- or regional-level policies have also been evaluated. The vast majority of these studies rely on NEMS, which is revised annually and is developed and operated by the U.S. Department of Energy (DOE) Energy Information Administration (EIA) to provide long-term energy forecasts.

Although the shape of the short-term natural gas supply curve is a transparent, exogenous input to NEMS, the model (like other energy models reviewed for this study) does not exogenously define a simple, transparent, long-term supply curve; instead, a variety of modeling assumptions and inputs are made that, when combined, implicitly define the long-term supply curve. For this reason, we must evaluate the long-term gas price effect of RE and $\mathrm{EE}$ by measuring the inverse price elasticity of supply in an implicit fashion - i.e., by reviewing modeling results.

We compiled information on a number of the relevant studies, ${ }^{16}$ including:

- five studies by the EIA focusing on national RPS policies, two of which model multiple RPS scenarios;

- six studies of national RPS policies by the Union of Concerned Scientists (UCS), three of which model multiple RPS scenarios, and one of which also includes aggressive energy efficiency investments;

- one study by the Tellus Institute that evaluates three different standards of a state-level RPS in Rhode Island (combined with RPS policies in Massachusetts and Connecticut); and

- an American Council for an Energy-Efficient Economy (ACEEE) study that explores the impact of national and regional RE and EE deployment on natural gas prices. ${ }^{17} 18$

\footnotetext{
${ }^{16}$ In addition to those mentioned here, a number of additional studies have evaluated this effect, but we were unable or did not attempt to obtain the detailed data needed to incorporate them into our analysis for this paper. These include: 1) Interlaboratory Working Group (2000), which evaluated EE and RE policies using NEMS; 2) a study of the New York RPS conducted by ICF Consulting (ICF 2003) using the Integrated Planning Model (IPM); 3) a study by the Center for Clean Air Policy to evaluate a state-level RPS and carbon restrictions in New York, using ICF's IPM model (CCAP 2003); 4) an analysis by the California Energy Commission of increased RE and EE investments, using the NANGAS model (CEC 2003); 5) an assessment of a comprehensive basket of carbon policies, using NEMS (Energy Innovations 1997); 6) an analysis of a host of policies to reduce carbon in the utility sector, using NEMS (Bailie et al. 2003a); 7) an assessment of the Climate Stewardship Act, using NEMS (Bailie et al. 2003b); 8) an analysis of a federal RPS by UCS, using RenewMarket, a simplified model based on a subset of the NEMS model (UCS 1999); 9) an analysis by Resources for the Future (RFF) of alternative national renewable energy policies, using the energy model Haiku (Palmer \& Burtraw 2004); and 10) an analysis of a Colorado RPS by UCS, using a modified version of NEMS (UCS 2004c).

${ }^{17}$ The regional scenarios consist of: one that examines EE and RE in California, Oregon, and Washington; another focused on EE and RE in the northeast and mid-Atlantic regions; a third that analyzes only RE in New York; a fourth that analyzes RE in Texas; and a fifth that focuses on RE and EE in Texas.

${ }^{18}$ In some instances, the studies included in our analysis actually incorporated multiple sensitivity cases in addition to different RPS standard levels (e.g., different cost caps or policy sunset provisions). In these instances, we selected just one of the sensitivity cases to report here.
} 
The EIA, UCS, and Tellus studies were all conducted using NEMS. However, because NEMS is revised annually and these studies were conducted during different years, they used different versions of NEMS. In addition, some of the studies summarized in this paper used modified versions of NEMS with, for example, different renewable energy and energy efficiency potential and cost assumptions. The ACEEE study used an energy model from Energy and Environmental Analysis (EEA) and, unlike the other studies, focused on the shorter term impacts of RE and EE investment in easing gas prices. ${ }^{19}$ As such, results from the ACEEE study are not entirely comparable to those reported for the other studies.

Though most of the results presented in this paper derive from a single energy model (NEMS), biasing the results somewhat, we benchmark these results against other commonly used energy models (Section 6) and against an historical literature that reviews the supply elasticity of energy commodities (Section 7). These comparisons allow greater confidence in our results.

The subsections below focus on the national results from these studies, specifically national gasconsumption and price impacts, gas-generation displacement, national electricity- and gas-bill impacts, and the $\$ / M W h$ value of RE and/or EE investments. The regional results of those studies that also explore regionally targeted RE and/or EE investments (Tellus and ACEEE) are presented in Section 5.

\subsection{National Gas-Consumption and Price Impacts}

Table 1 summarizes some of the key national results of these studies. ${ }^{20}$ Key findings shown in Table 1 include:

- Electric Bills: Some of the studies predict that increased RE generation (and EE, if applicable) will modestly increase retail electricity prices on a national average basis, though more recent studies have sometimes found small price reductions (due to improved renewable economics relative to gas-fired generation).

- Gas Consumption: Increased RE and EE also cause a reduction in national natural gas consumption, ranging from less than $1 \%$ to nearly $30 \%$ depending on the study.

- Wellhead Gas Prices: Reduced gas consumption suppresses natural gas prices, with price reductions ranging from virtually no change in the national average wellhead price to a $50 \%$ reduction in that price. As one might expect, the more significant reductions in gas

\footnotetext{
${ }^{19}$ EEA's Gas Market Data and Forecasting System is a full supply-demand equilibrium model of the North American gas market. The model solves for monthly market-clearing gas prices throughout North America, given different supply/demand assumptions for each of the model's nodes. On the supply side, prices are determined by production and storage price curves, and by "pipeline discount" curves. On the demand side, prices are represented by a curve that captures fuel switching behavior (ACEEE 2003).

${ }^{20}$ Table 1 presents the projected impacts of increased RE and EE deployment in each study relative to some baseline. The baselines differ from study to study, which partially explains why, for example, a $10 \%$ RPS in two studies can lead to different impacts on renewable generation (in TWh and in \% increase in renewable generation, above the baseline). The impact on renewable generation also varies because of assumed cost caps used in some studies or sunset provisions that in some studies terminate the RPS in a certain year, leading to fewer modeled renewable capacity additions in later years of the study because there are fewer years under the RPS in which to recoup investment costs. Additional variations among model runs include renewable technology and cost assumptions and the treatment of the federal production tax credit.
} 
consumption and prices are typically found in studies that evaluated aggressive RE and EE deployment.

Table 1. Summary of Results from Past RE/EE Deployment Studies

\begin{tabular}{|c|c|c|c|c|c|}
\hline Author & RPS/EE & $\begin{array}{l}\text { Increase in U.S. } \\
\text { RE Generation } \\
\text { TWh (\% of total } \\
\text { generation) }\end{array}$ & $\begin{array}{l}\text { Reduction in U.S. } \\
\text { Gas Consumption } \\
\text { Quads (\%) }\end{array}$ & $\begin{array}{l}\text { Gas Wellhead } \\
\text { Price Reduction } \\
\text { \$/MMBtu (\%) } \\
\end{array}$ & $\begin{array}{l}\text { Retail Electric } \\
\text { Price Increase } \\
\text { Cents/kWh (\%) }\end{array}$ \\
\hline EIA (1998) & $10 \%-2010(\mathrm{US})$ & $336(6.7 \%)$ & $1.12(3.4 \%)$ & $0.34(12.9 \%)$ & $0.21(3.6 \%)$ \\
\hline EIA (1999) & $7.5 \%-2020(\mathrm{US})$ & $186(3.7 \%)$ & $0.41(1.3 \%)$ & $0.19(6.6 \%)$ & $0.10(1.7 \%)$ \\
\hline EIA (2001) & $10 \%-2020$ (US) & $335(6.7 \%)$ & $1.45(4.0 \%)$ & $0.27(8.4 \%)$ & $0.01(0.2 \%)$ \\
\hline EIA (2001) & 20\%-2020 (US) & $800(16.0 \%)$ & $3.89(10.8 \%)$ & $0.56(17.4 \%)$ & $0.27(4.3 \%)$ \\
\hline EIA (2002a) & 10\%-2020 (US) & $256(5.1 \%)$ & $0.72(2.1 \%)$ & $0.12(3.7 \%)$ & $0.09(1.4 \%)$ \\
\hline EIA (2002a) & $20 \%-2020$ (US) & $372(7.4 \%)$ & $1.32(3.8 \%)$ & $0.22(6.7 \%)$ & $0.19(2.9 \%)$ \\
\hline EIA (2003) & $10 \%-2020(\mathrm{US})$ & $135(2.7 \%)$ & $0.48(1.4 \%)$ & $0.00(0.0 \%)$ & $0.04(0.6 \%)$ \\
\hline UCS (2001) & $20 \%-2020, \& \mathrm{EE}(\mathrm{US})$ & $353(7.0 \%)$ & $10.54(29.7 \%)$ & $1.58(50.8 \%)$ & $0.17(2.8 \%)$ \\
\hline UCS (2002a) & $10 \%-2020(\mathrm{US})$ & $355(7.1 \%)$ & $1.28(3.6 \%)$ & $0.32(10.4 \%)$ & $-0.18(-2.9 \%)$ \\
\hline UCS (2002a) & $20 \%-2020$ (US) & $836(16.7 \%)$ & $3.21(9.0 \%)$ & $0.55(17.9 \%)$ & $0.19(3.0 \%)$ \\
\hline UCS (2002b) & $10 \%-2020(\mathrm{US})$ & $165(3.3 \%)$ & $0.72(2.1 \%)$ & $0.05(1.5 \%)$ & $-0.07(-1.1 \%)$ \\
\hline UCS (2003) & 10\%-2020 (US) & $185(3.7 \%)$ & $0.10(0.3 \%)$ & $0.14(3.2 \%)$ & $-0.14(-2.0 \%)$ \\
\hline UCS (2004a) & $10 \%-2020$ (US) & $181(3.6 \%)$ & $0.49(1.6 \%)$ & $0.12(3.1 \%)$ & $-0.12(-1.8 \%)$ \\
\hline UCS (2004a) & $20 \%-2020(\mathrm{US})$ & $653(13.0 \%)$ & $1.80(5.8 \%)$ & $0.07(1.87 \%)$ & $0.09(1.3 \%)$ \\
\hline UCS (2004b) & $10 \%-2020($ US) & $277(5.5 \%)$ & $0.62(2.0 \%)$ & $0.11(2.6 \%)$ & $-0.16(-2.4 \%)$ \\
\hline UCS (2004b) & $20 \%-2010$ (US) & $647(12.9 \%)$ & $1.45(4.7 \%)$ & $0.27(6.7 \%)$ & $-0.19(-2.9 \%)$ \\
\hline Tellus (2002) & $10 \%-2020(\mathrm{RI})$ & $31(0.6 \%)$ & $0.13(0.4 \%)$ & $0.00(0.0 \%)$ & $0.02(0.1 \%)$ \\
\hline Tellus (2002) & $15 \%-2020(\mathrm{RI})$ & $89(1.8 \%)$ & $0.23(0.7 \%)$ & $0.01(0.4 \%)$ & $-0.05(-0.3 \%)$ \\
\hline Tellus, (2002) & $20 \%-2020(\mathrm{RI})$ & $98(2.0 \%)$ & $0.28(0.8 \%)$ & $0.02(0.8 \%)$ & $-0.07(-0.4 \%)$ \\
\hline ACEEE (2003) & $6.3 \%-2008, \&$ EE (US) & NA & $1.37(5.4 \%)$ & $0.74(22.1 \%)$ & NA \\
\hline
\end{tabular}

Notes:

- $\quad$ The data for the ACEEE study are for 2008, the final year of that study's forecast. All other data are for 2020.

- All dollar figures are in constant $2000 \$$.

- The increase in U.S. RE generation reflects the TWh and \% increase relative to the reference case scenario for the year 2020. The \% figures do not equate to the size of the RPS for a variety of reasons: 1) existing RE generation and new RE generation that comes on line in the reference case may also be eligible for the RPS, and 2 ) the RPS is not always achieved, given assumed cost caps in some studies.

- The reference case in most studies reflects an EIA AEO reference case, with some studies making adjustments based on more recent gas prices or altered renewable-technology assumptions. The one exception is UCS (2003), in which the reference case reflects a substantially higher gas-price environment than the relevant AEO reference case.

- The Tellus study models an RPS for Rhode Island, also including the impacts of the Massachusetts and Connecticut RPS policies. All the figures shown in this table for the Tellus study, as well as ACEEE (2003), are for the predicted national-level impacts of the regional policies that were evaluated.

Wellhead price reductions translate into reduced bills for natural gas consumers and moderate the expected RE-induced increase in electricity prices predicted by many of the studies by reducing the price of gas delivered to the electricity sector. As shown in Figure 4, with some 
exceptions, the absolute reduction in delivered natural gas prices for the electricity and nonelectricity sectors largely mirrors the reduction in wellhead gas prices shown in Table 1 . This suggests that changes in wellhead prices flow through to delivered prices for all U.S. consumers - even those consumers located in regions that do not experience significant RE and EE development - on an approximate one-for-one basis.

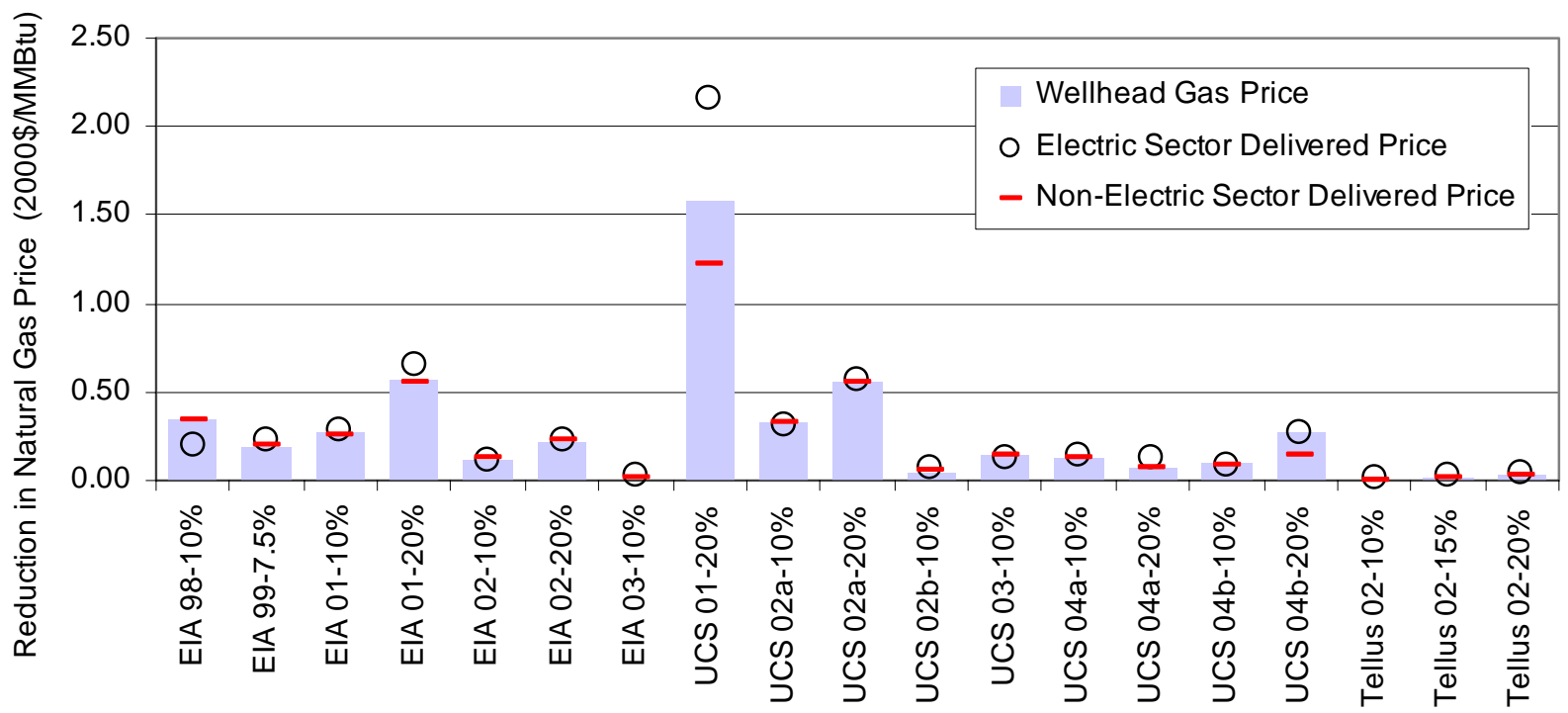

Figure 4. The Impact of RE/EE Deployment on Wellhead and Delivered Gas Prices

Focusing on just those studies that exclude EE deployment (i.e., all but ACEEE 2003 and UCS $2001){ }^{21}$ Figure 5 presents the impact of increased RE generation on the displacement of national gas consumption in 2020 (see Appendix A for more detailed annual data on natural gas displacement). Figure 6, meanwhile, shows the impact of increased RE generation on the national average wellhead price of natural gas.

${ }^{21}$ We exclude the two studies that involve EE deployment here only to simplify the graphical results. 


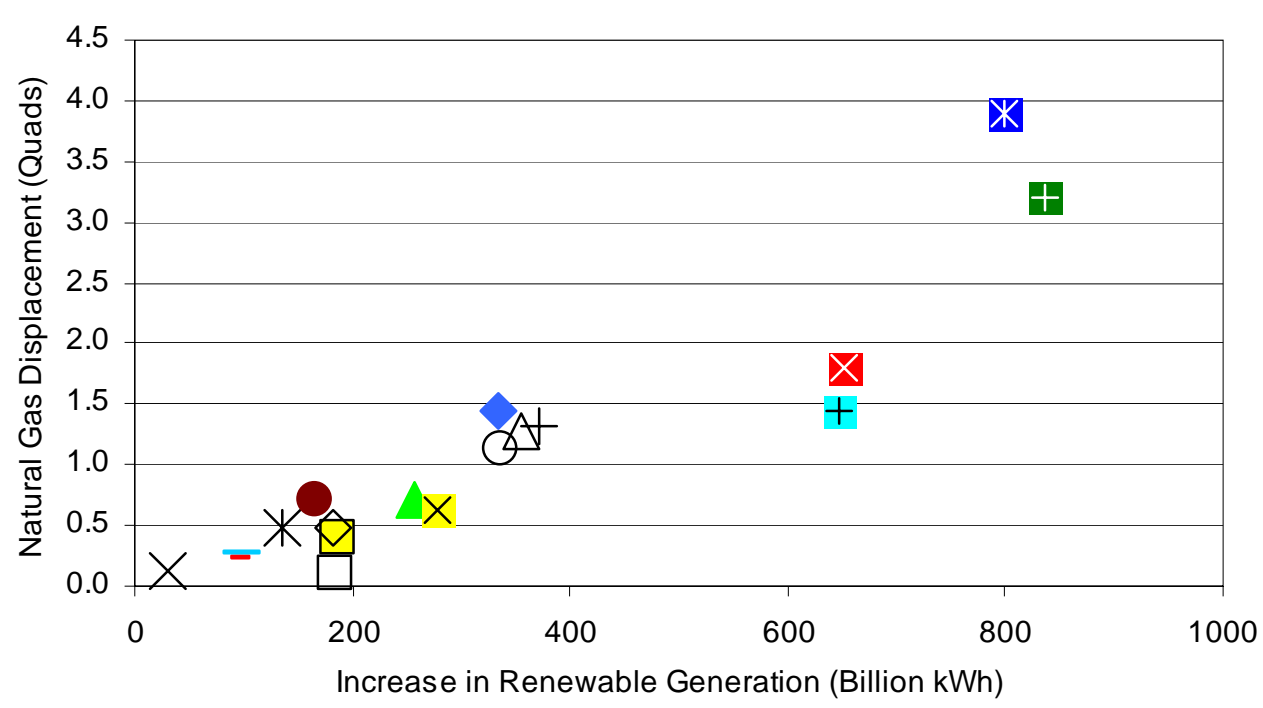

O EIA $98-10 \%$

口EIA $99-7.5 \%$

EIA 01-10\%

XEIA 01-20\%

$\triangle$ EIA 02-10\%

+ EIA 02-20\%

* EIA 03-10\%

$\triangle$ UCS $02 \mathrm{a}-10 \%$

+UCS 02a-20\%

- UCS $02 \mathrm{~b}-10 \%$

口UCS 03-10\%

$\triangle$ UCS $04 a-10 \%$

XUCS $04 a-20 \%$

XUCS $04 b-10 \%$

+ UCS 04b-20\%

$\times$ Tellus $02-10 \%$

- Tellus 02-15\%

- Tellus 02-20\%

Figure 5. Forecasted Natural Gas Displacement in 2020

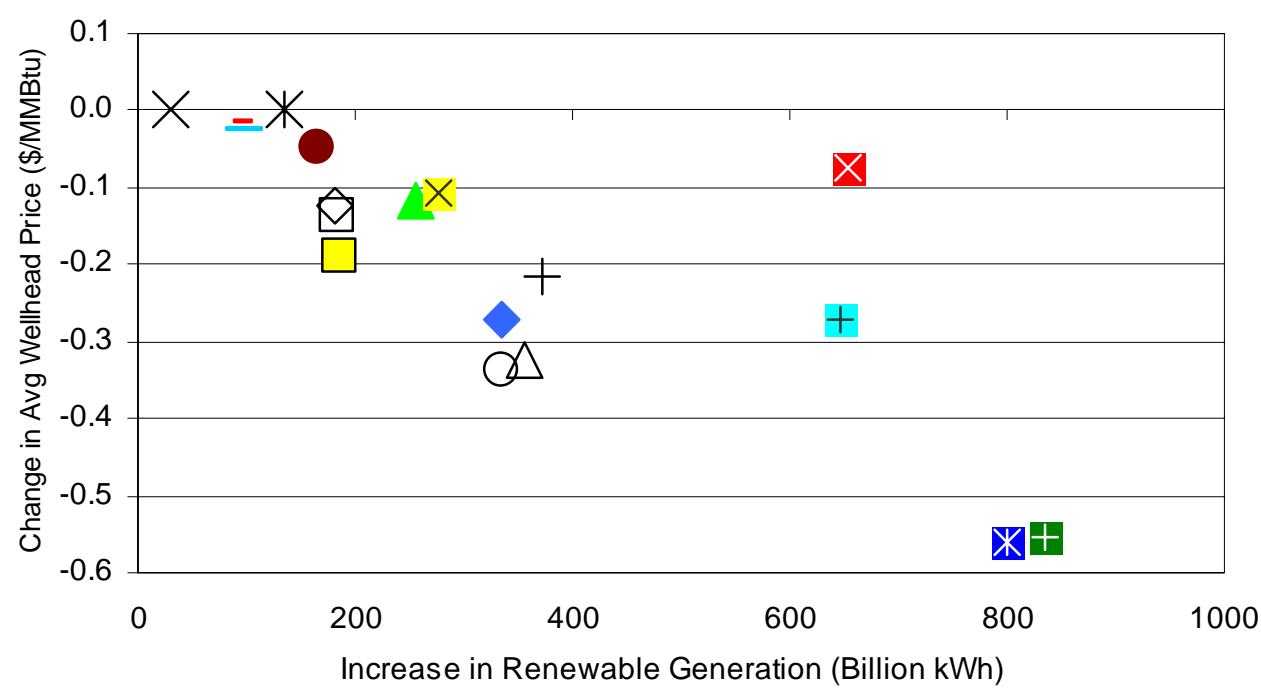

O EIA $98-10 \%$ $\square$ EIA $99-7.5 \%$ $\rightarrow$ EIA 01-10\% XEIA 01-20\% $\triangle$ EIA $02-10 \%$ + EIA 02-20\% * EIA 03-10\% $\triangle$ UCS $02 \mathrm{a}-10 \%$ +UCS $02 \mathrm{a}-20 \%$ - UCS $02 \mathrm{~b}-10 \%$ $\square$ UCS 03-10\% $\checkmark$ UCS $04 a-10 \%$ XuCS $04 a-20 \%$ XUCS $04 \mathrm{~b}-10 \%$ + UCS 04b-20\% $\times$ Tellus $02-10 \%$

- Tellus 02-15\%

- Tellus $02-20 \%$

Figure 6. Forecasted Natural Gas Wellhead Price Reduction in 2020

\subsection{Gas-Generation Displacement and Effective Heat Rates}

Although this is not shown explicitly in the preceding tables and figures, RE and EE are generally expected to lead to greater reductions in gas consumption (and, therefore, prices) in the studies that rely on lower gas-price forecasts in the business-as-usual scenario. More recent studies, which often rely on higher gas-price forecasts (e.g., UCS 2004a, 2004b), generally find less gas displacement (and greater coal displacement) over time as coal out-competes gas for new additions; this effect can be seen in the relatively lower gas displacement and price reduction seen under the 20\% RPS in UCS (2004a) and UCS (2004b), shown in Figures 5 and 6. 
This effect is shown graphically in more detail in Appendix A; the newest studies of national RPS policies find that each MWh of incremental RE displaces as little as $0.34 \mathrm{MWh}$ of natural gas generation on average, though some earlier studies show an average displacement of more than $0.75 \mathrm{MWh}^{22}$ In a high-gas-price environment, this effect may mitigate the benefit of RE and EE in reducing gas prices. ${ }^{23}$ Although it is possible that increased RE and EE may also put downward pressure on coal prices, the elasticity of coal prices to altered demand conditions is likely to be far lower than that of natural gas (see, for example, Figure 15 later in this paper), suggesting that the impact of RE and EE on coal prices is probably modest relative to their impact on gas prices. ${ }^{24}$

\subsection{National Electricity- and Gas-Bill Impacts}

Figures 4 through 6, along with Table 1, clearly show that increased RE and EE are predicted to reduce natural gas consumption and prices while retail electricity prices are predicted to rise in at least some instances. The net predicted effect on consumer energy bills could be positive or negative, depending on the relative magnitude of the electricity- and natural gas-bill effects.

Figure 7 presents these offsetting effects for a subset of the studies we reviewed. ${ }^{25}$ Although there are variations among the different studies, the NPV of the cumulative (2003-2020) predicted increase in consumer electricity bills (if any) in the RPS cases compared to the reference case is often on the same order of magnitude as the NPV of the predicted decrease in consumer natural gas bills. ${ }^{26}$ From an aggregate consumer perspective, therefore, the net consumer cost of these policies is typically predicted to be rather small, with 12 of 15 RPS analyses even showing net consumer savings (i.e., negative cumulative bill impacts). ${ }^{27}$

\footnotetext{
${ }^{22}$ Appendix A also shows the effective heat rate of the gas generation that is displaced in the national RPS analyses, which averages approximately $9,000 \mathrm{Btu} / \mathrm{kWh}$ in the early years, dropping to $\sim 7,500 \mathrm{Btu} / \mathrm{kWh}$ in the later years.

${ }^{23}$ Similarly, as RE and EE increase, gas prices are expected to decrease, making gas generation a more potent competitor to RE and EE.

${ }^{24}$ Despite this, the impact of RE and EE on coal prices may still merit some additional exploration. Also, RE and EE may affect oil prices because of a direct (but likely modest) displacement of oil-fired generation or from the indirect link between gas and oil prices (i.e., reduced gas prices will put downward pressure on oil prices because of the possibility of fuel substitution).

${ }^{25}$ Figure 7 shows the energy bill impacts only for the national RPS studies for which these data were available [i.e., it excludes Tellus (2002) as well as the two studies in which EE investments were also modeled]. Only "private" costs are considered (i.e., excluding environmental externalities), and a $7 \%$ real discount rate is used. The $7 \%$ discount rate is used to be consistent with recommendations from the Office of Management and Budget. Note, however, that Awerbuch (2003) and others recommend far lower risk-adjusted discount rates, especially for natural gas costs. If such discount rates were used, the NPV of consumer gas savings would be even higher than shown in Figure 7.

${ }^{26}$ During the past several years, as forecasted natural gas prices have risen, the aggregate predicted consumer impacts of an RPS should, all else being equal, have become more positive. To some degree, this is born out by Figure 7.

${ }^{27}$ In several of these studies, RPS cost caps are reached, ensuring that consumers pay a capped price for some number of proxy renewable energy credits (and leading to increased electricity prices) while not obtaining the benefits of increased RE generation on natural gas prices. Accordingly, if anything, Figure 7 underestimates the possible consumer benefits of a well-designed renewable energy program with less-binding cost caps.
} 


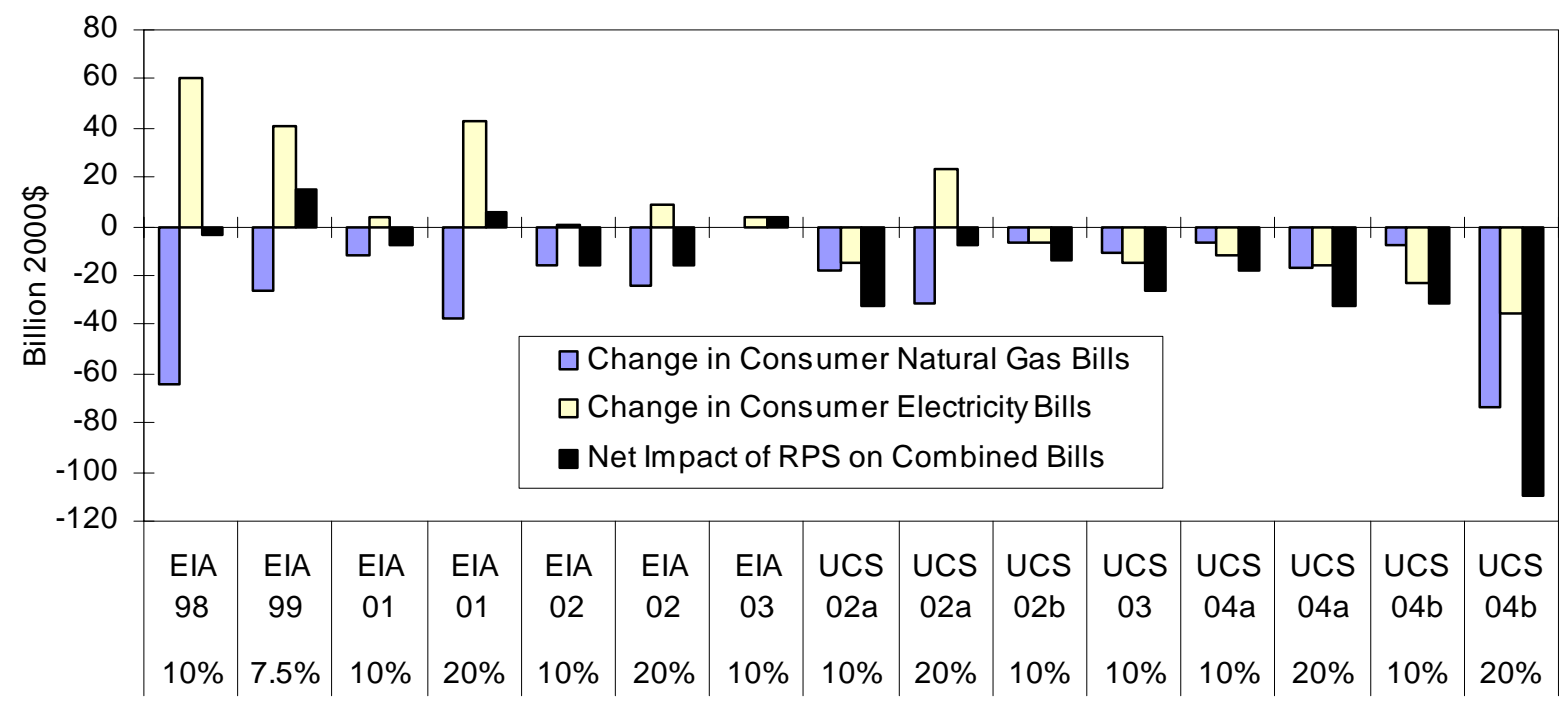

Figure 7. NPV of RPS Impacts on Natural Gas and Electricity Bills (2003-2020, $7 \%$ real discount rate)

\subsection{The Value of Renewable Energy, in \$/MWh}

By putting downward pressure on natural gas prices and bills, increased RE and EE provide a significant benefit to consumers, based on the studies reviewed here. But how large is that national impact, in dollars per MWh of incremental renewable energy?

Considering the predicted reduction in consumer gas bills as well as an assumed one-for-one pass-through of reductions in gas costs in the electricity sector to consumers, Figure 8 shows the range of consumer benefits delivered with increased renewable energy generation, by study (not including those studies that also include energy efficiency investments), expressed in terms of \$ per MWh of incremental renewable energy. ${ }^{28}$

Results from these studies suggest that each MWh of incremental renewable energy production provides, on average, national consumer benefits in the form of gas savings in the range of $\$ 6 / \mathrm{MWh}$ to $\$ 35 / \mathrm{MWh}$, with a central range of about $\$ 7.50$ to $\$ 20 / \mathrm{MWh}$. Variations in this value are caused by different implied inverse price elasticities of natural gas supply (see Section 4), and by differences in the amount of gas displacement caused by renewable energy (see Appendix A). Even at the low end of the range, however, these benefits are sizable.

\footnotetext{
${ }^{28}$ Note that this "value" is presented in \$ per MWh of incremental renewable energy, and not as \$/MWh in reduced consumer bills.
} 


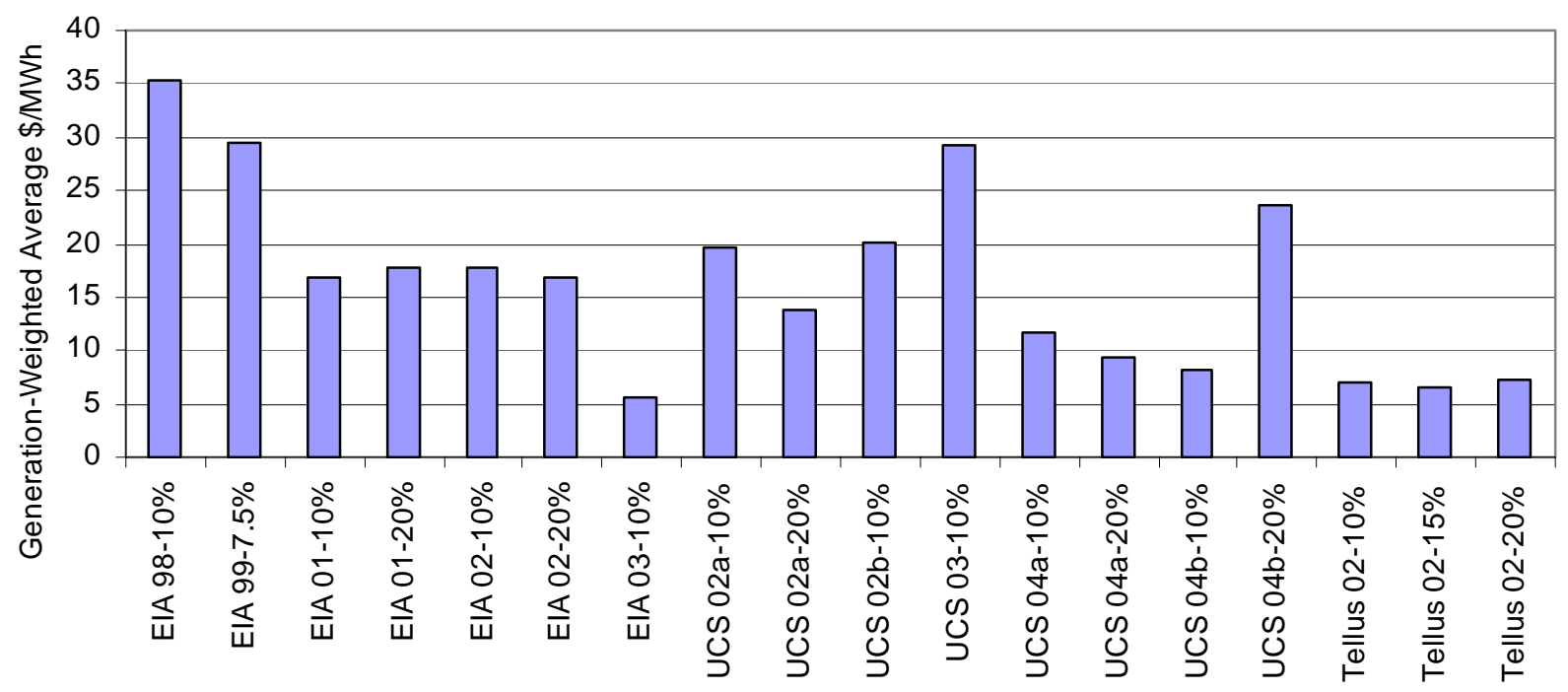

Figure 8. Consumer Gas-Savings Benefits of Increased RE Production (in \$/MWh) ${ }^{29}$

${ }^{29}$ We weight the annual benefit of gas bill savings per MWh by the amount of yearly renewable generation to derive this weighted average figure. Yearly data are averaged over the following period: from the first year in which incremental renewable energy supply exceeds 10 billion kWh (such that we ignore early year "noise" in the data) to the last year of the forecast period, either 2020 or 2025 (depending on the study). 


\section{Summary of Implied Inverse Price Elasticities of Supply}

Ignoring the different impacts of RE and $\mathrm{EE}$ deployment on gas consumption among studies (see Appendix A and Figure 5), we can compare the natural gas price response among studies by calculating the inverse price elasticity of supply implied by the results of each study, for each forecast year. This calculation requires annual data on the predicted average national wellhead price of natural gas and total natural gas consumption in the United States (U.S.) for both the business-as-usual baseline scenario and the policy scenario of increased RE and/or EE deployment. ${ }^{30}$ With the exception of the ACEEE study, the resulting inverse elasticities can be considered long-term elasticities. ${ }^{31}$

Figure 9 compares long-term implicit inverse elasticities among studies for the years 2000-2025 (excluding the ACEEE 2003 results, which are presented later). If nothing else, the figure shows that implied inverse elasticities exhibit a great deal of variation. Although some of the studies show a reasonable level of consistency in the inverse elasticity over time, others show large swings from year to year. This is especially (though not always) true when the aggregate reduction in gas demand is small, which leads to substantial "noise" in the modeling results. Swings in the inverse elasticity of the magnitude shown in some of the studies may not be within reasonable bounds, and further research is required to better understand these inter-annual trends.
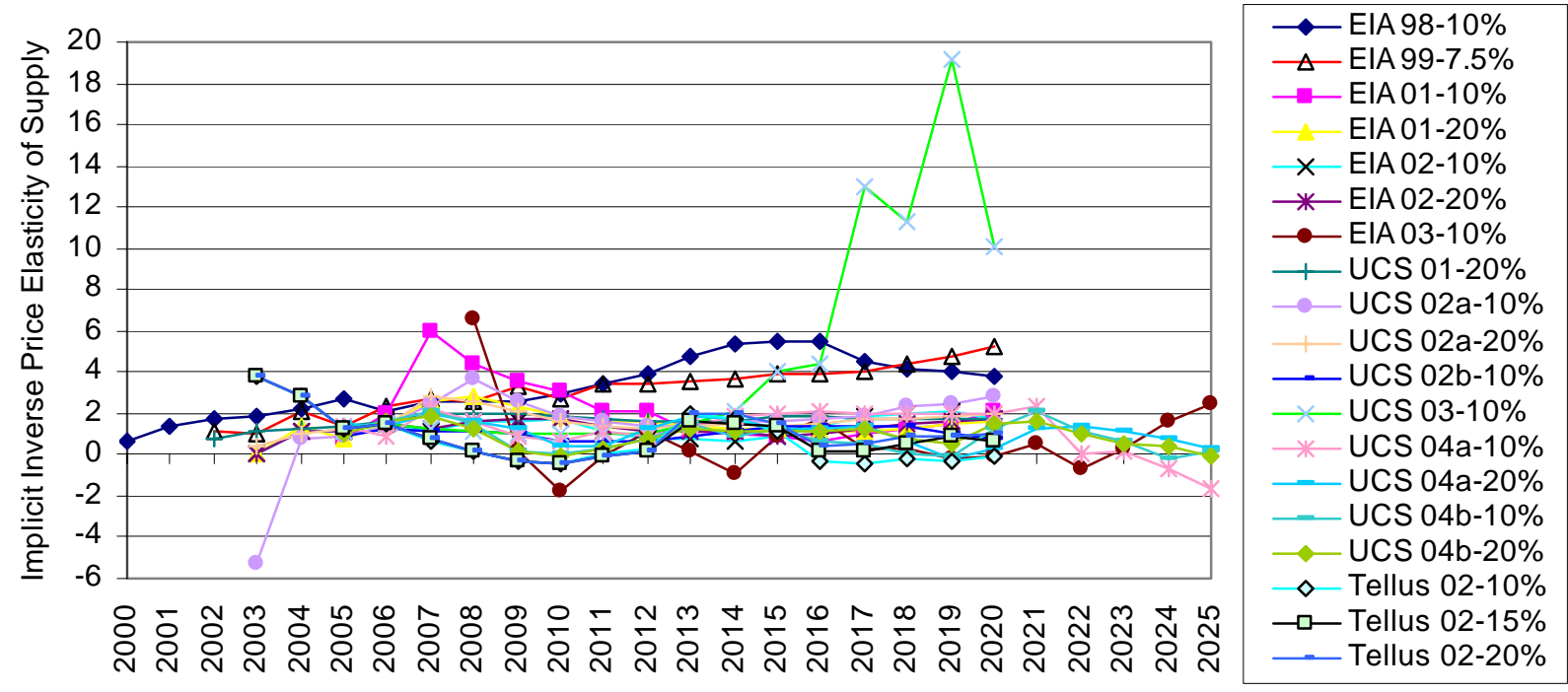

Figure 9. Annual Implicit Inverse Price Elasticities of Supply

\footnotetext{
${ }^{30}$ The specific calculation is:

$E^{-1}=\left(\right.$ Wellhead Price $_{\text {business-as-usual }} /$ Wellhead Price policy $\left._{1}-1\right) /\left(\right.$ Gas Demand $_{\text {business-as-usual }} /$ Gas Demand $\left._{\text {policy }}-1\right)$ The inverse elasticity calculations presented here use U.S. price and quantity data under the assumption that the current market for natural gas is more regional than worldwide in nature (Henning, Sloan \& de Leon 2003). Of course, the market for natural gas consumed in the U.S. is arguably a North American market, including Canada and Mexico, with LNG expected to play an increasing role in the future. Trade with Mexico is relatively small, however, and Canadian demand for gas is relatively small compared to U.S. demand. LNG, meanwhile, remains a modest contributor to total U.S. consumption.

${ }^{31}$ We reiterate that our review of NEMS output in the national RPS studies shows that predicted natural gas prices in NEMS do not appear to be more sensitive to demand changes in the short term than in the long term. Because of this, one might question NEMS' treatment of short-term natural gas supply elasticities.
} 
Because relying on the implied inverse elasticity for any single year could be misleading, Figure 10 summarizes the average value of the implied inverse elasticities over an extended forecast period. ${ }^{32}$ Despite substantial variations among studies and results for individual years, there is some consistency in the average long-term inverse elasticities; the overall range is between 0.7 and 4.7, with elasticites from 13 of 19 analyses (all of which use NEMS) falling between 0.8 and $2.0 .^{33}$ This means that each $1 \%$ reduction in national, natural gas demand is expected to lead to a $0.8 \%$ to $2 \%$ reduction in wellhead gas prices.

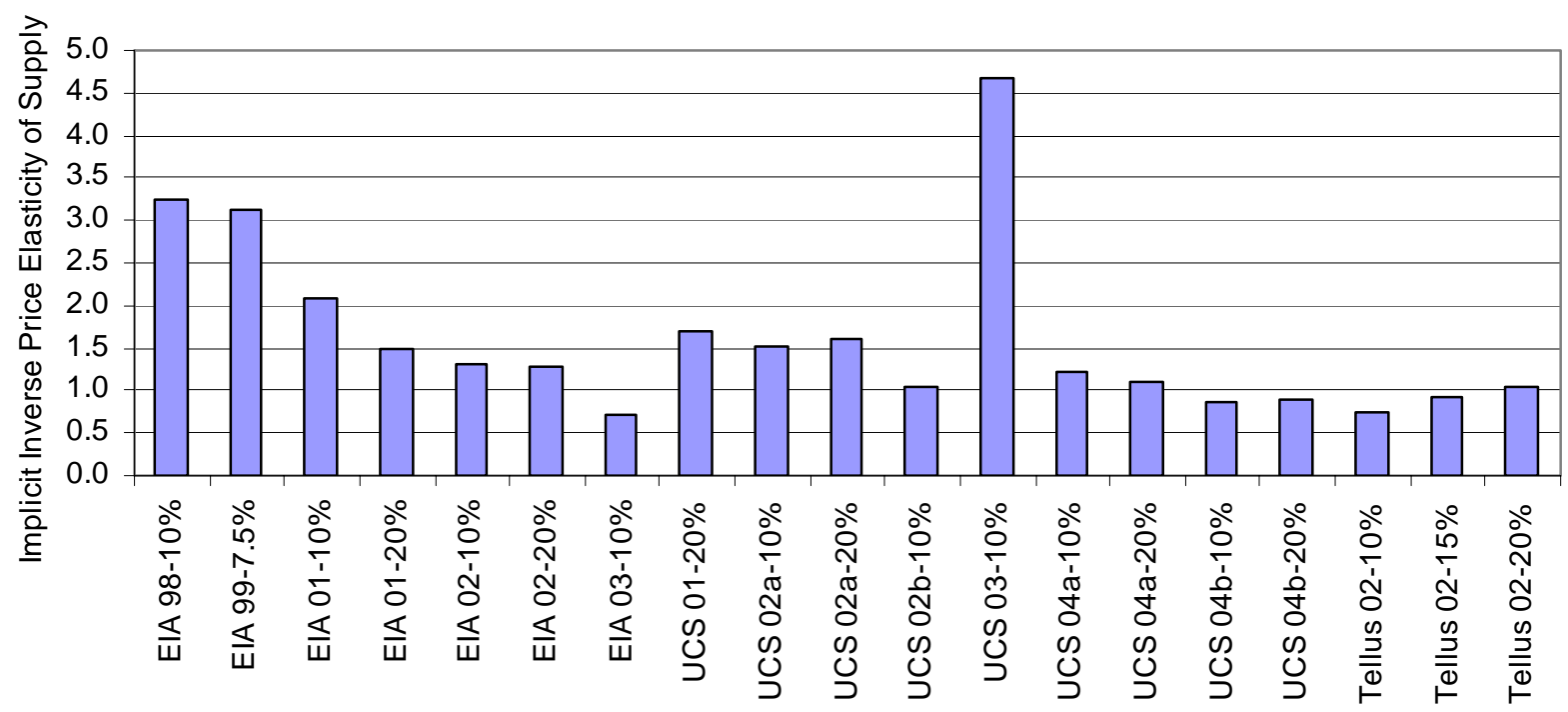

Figure 10. Average Inverse Price Elasticities of Supply

Though the implied inverse elasticities derived from NEMS appear to represent the long-term supply curve for natural gas, this is not the case in the ACEEE study. The ACEEE study reports the impact of increased RE/EE deployment over a shorter period (2004-2008) than the other studies and uses a gas-market model from EEA that reports impacts on a more disaggregated basis by region and by time interval than NEMS, considering regional transportation and supply constraints. ACEEE purposefully studied this shorter time period in order to determine to what degree RE and EE could ease the short-term burden on consumers of heightened gas prices. By looking at shorter-term influences, the ACEEE study also reflects, to a greater degree than other studies, natural gas transportation constraints.

Although the ACEEE study analyzed the potential impact of both state and regional RE and EE deployment (see Section 5), Figure 11 only reports the results of the national RE/EE deployment scenario. This figure shows that implied inverse elasticities are high, more than 10 , in the early years; by 2008, the inverse elasticity drops to four, which is still more than twice as high as the

\footnotetext{
${ }^{32}$ Average inverse elasticities are calculated as the average of each year's inverse elasticity, from the first year in which incremental renewable energy production exceeds 10 billion $\mathrm{kWh}$ (so that we ignore early year "noise" in the data) to the last year of the forecast period, 2020 or 2025, depending on the study.

${ }^{33}$ The average inverse elasticity from UCS (2003) is substantially higher than that from most of the other studies. As noted earlier, UCS (2003) evaluated the potential impact of an RPS under a scenario of higher gas prices than in a typical AEO reference case, so that study is not strictly comparable to the others covered in this paper (specifically, the UCS study includes a more constrained gas supply than most of the other analyses, especially in the later years, and so is arguably measuring changes along a steeper portion of the supply curve).
} 
average long-term inverse elasticity implicit in the latest versions of NEMS, though it is consistent with other recent long-term analyses conducted with the EEA model (see Section 6). ${ }^{34}$

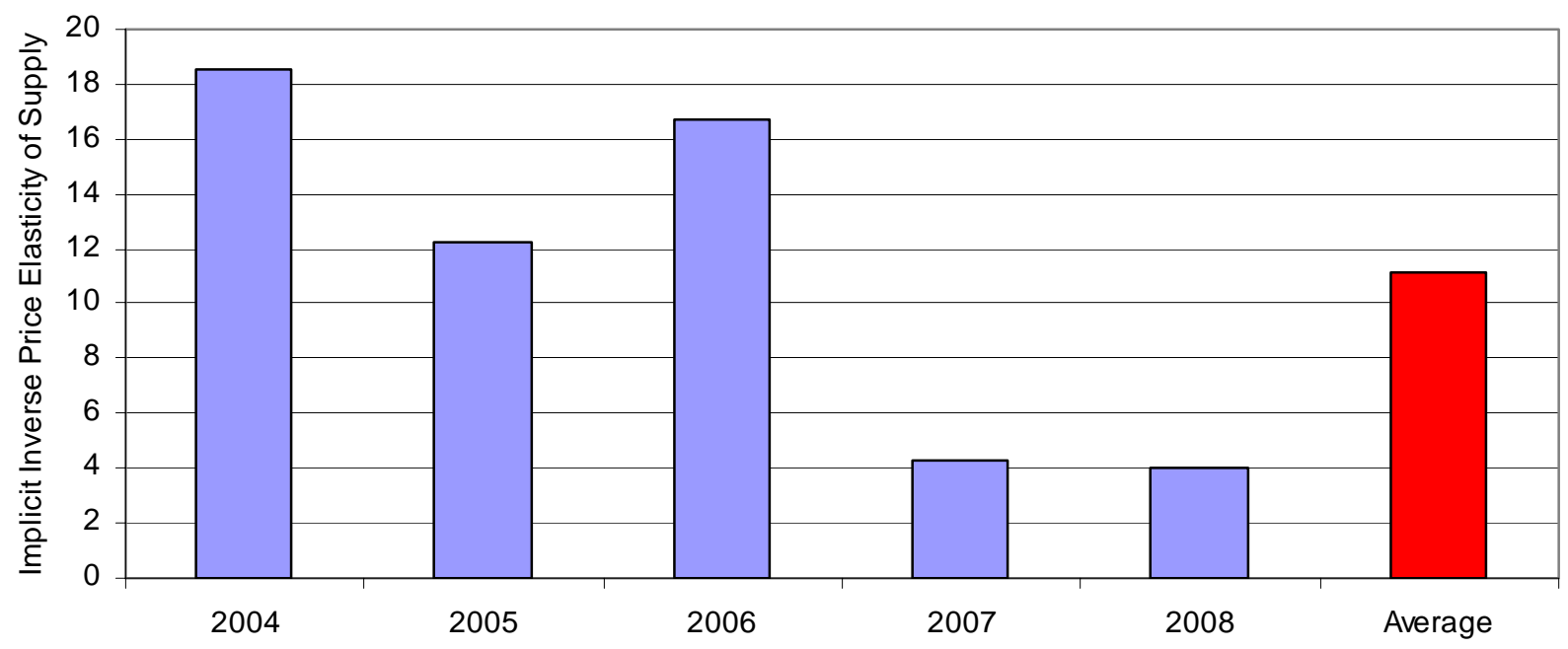

Figure 11. Implicit Inverse Price Elasticities in ACEEE (2003)

Because the other studies reviewed in this paper do not seek to present short-term impacts at the same level of disaggregation as ACEEE, it is difficult to compare the ACEEE results with those of other studies. The national short-term impacts forecast by ACEEE are aggressive, however, and at the least should not be extrapolated to later years (but should instead be considered shorter-term impacts that are unlikely to persist). By the same token, the ACEEE results demonstrate that the positive impacts of increased RE and EE may be more significant in the short run than is estimated by other modeling studies whose approaches are arguably better able to address longer-term influences.

\footnotetext{
${ }^{34}$ The natural gas price data used to construct the inverse elasticities implicit in the ACEEE results are projected Henry Hub prices; the previously mentioned studies relied on wellhead price projections. Because Henry Hub prices are typically higher than wellhead prices, inverse elasticities calculated with Henry Hub data will be lower than would be the case if wellhead prices were used.
} 



\section{Evaluating Regional Impacts}

Even regionally focused RE and EE investments will have a national impact on natural gas prices, as shown in the results presented earlier from Tellus (2002). It is plausible to think, however, that the national, longer-term elasticity figures presented earlier may not adequately capture the differential effects on the specific region where regionally targeted investments are made. This is especially true in the short term when gas prices are likely to be highly sensitive to demand in certain transportation-constrained regions. Henning, Sloan, and de Leon (2003), for example, note that in both California and New York City, natural gas demand at times exceeds available pipeline capacity, allowing prices to rise to reflect scarcity. In these regions, RE and EE investments may provide significant near-term economic benefits to consumers. In the longerterm, if these transportation constraints are alleviated, differential regional effects will not last.

Of the studies reviewed in this paper, only Tellus (2002) and ACEEE (2003) explicitly address the impacts of regionally focused RE and EE deployment. ${ }^{35}$ We presented the national results of these studies in Section 3; in this section, we turn to their regional results. To expand our understanding of the possibility of differential regional effects, we also conduct our own analysis using NEMS.

In all cases, we specifically report what we call the regional multiplier, which is the ratio of the reduction in average end-use gas prices at the regional level to the reduction in average end-use gas prices at the national level. A multiplier greater than one suggests that the impact on gas prices is greater at the regional level than it is at the national level. All else being equal, we would expect regional multipliers to start at greater than one, especially in transportationconstrained regions, reflecting at a minimum the impact of RE and EE on delaying needed pipeline expansions. Assuming that transportation constraints ease over time, regional multipliers will tend to decline toward one. ${ }^{36}$

\subsection{Regional Multipliers from Tellus (2002) and ACEEE (2003)}

Tellus (2002) evaluates the impact of RPS policies in New England. The results presented in Figure 12 show that the regional multipliers associated with Tellus (2002) do not behave in the expected fashion, with little explainable trend over time. We suspect that the "noise" in these results is caused by the relatively modest incremental $\mathrm{RE}$ additions that in a complex national energy model such as NEMS created a "signal-to-noise" ratio that is too low to identify clear trends.

\footnotetext{
${ }^{35}$ UCS (2004c) uses a modified version of NEMS to analyze a Colorado RPS, but direct comparisons between its regional and national results - our specific area of interest in this section - are not possible because of the modeling methodology employed. Similarly, CEC (2003) analyzes the impact of reductions in California gas demand on regional gas prices. Because the CEC study does not comprehensively report its national results, however, the data cannot be compared to data presented in this section.

${ }^{36}$ NEMS and other integrated energy models generally assume pipeline additions and expansions when economic conditions warrant.
} 


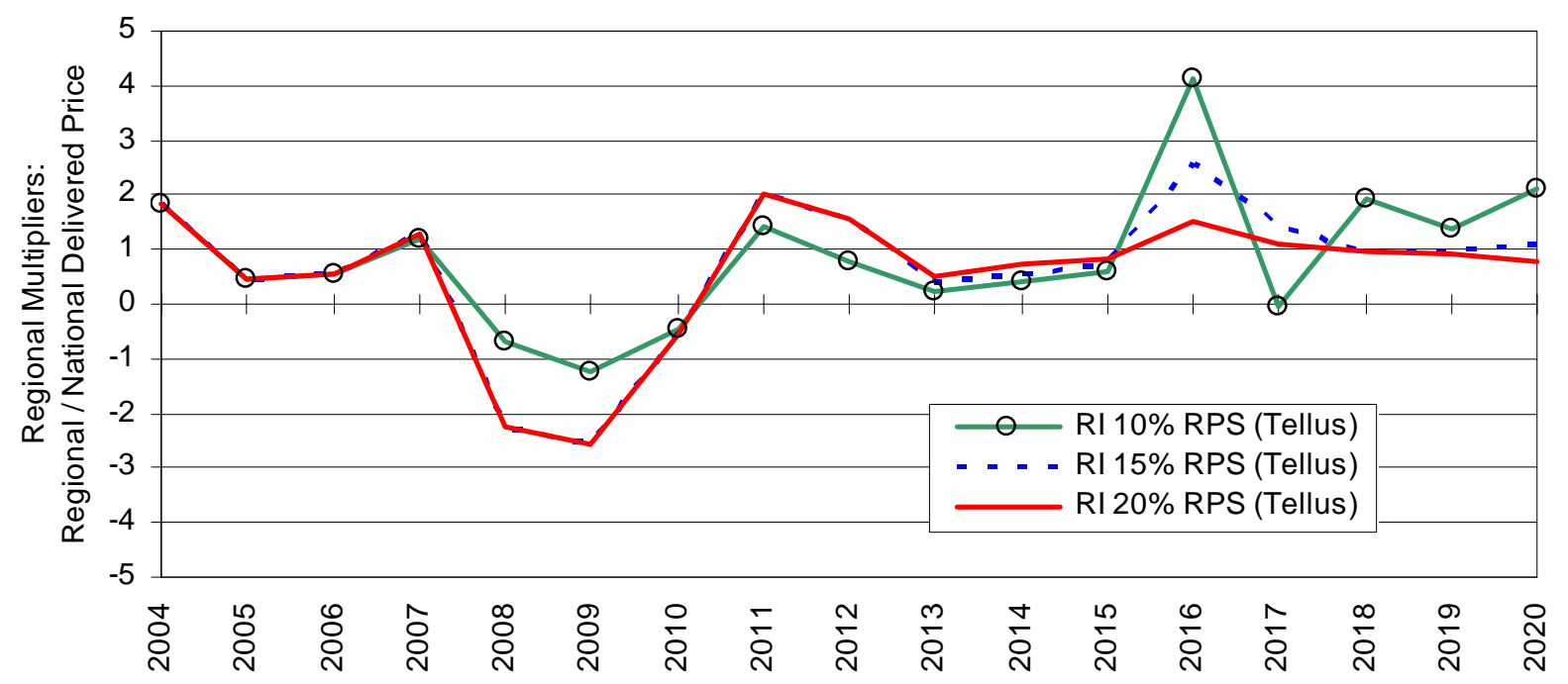

Figure 12. Regional Multipliers for Tellus (2002)

ACEEE (2003) examined five regional scenarios, whose regional-to-national delivered price multipliers are shown in Figure 13. The EEA model used in the ACEEE study has a more detailed representation of regional prices than NEMS, arguably making it better suited for assessing the near-term regional impacts of regionally targeted RE and EE investments, especially in transportation-constrained regions. NEMS contains some regional representation, but its assessment of inter-state pipeline and local distribution costs is largely determined on a cost-of-service basis (i.e., not reflecting scarcity). This makes the ACEEE results not entirely comparable to those of NEMS.

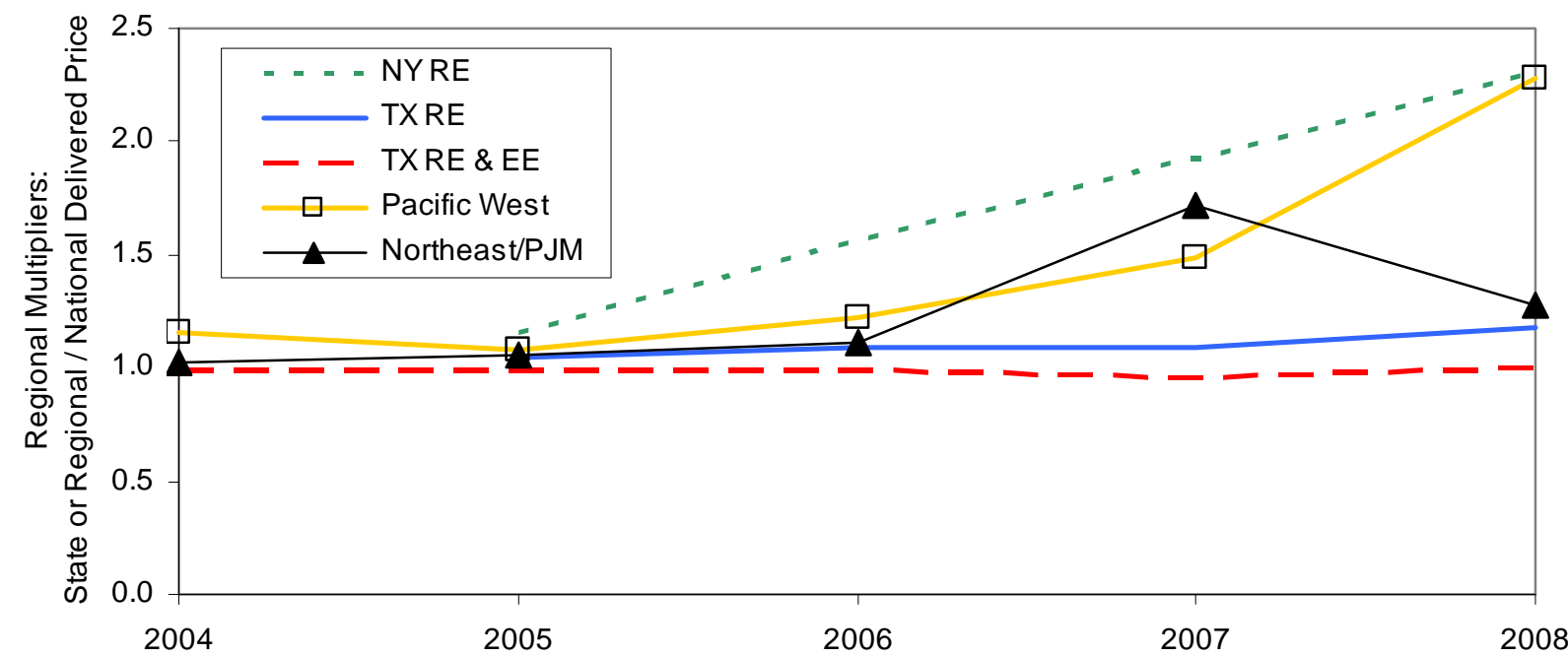

Figure 13. Regional Multipliers for ACEEE (2003)

Regions analyzed by ACEEE were selected in part because of their severe natural gas transportation constraints, constraints that could plausibly be eased by RE and EE investments. Although the regional multipliers are at or above one, as expected, they do not systematically 
drop over time (on the contrary, many of them increase). These results may reflect a plausible assumption in the ACEEE study of worsening pipeline constraints over the coming several years (even with the increased RE and EE), at least in the regions analyzed by ACEEE (excepting Texas, which does not experience transportation constraints and where the multiplier is near one). Worsening transportation constraints could result in increasing regional multipliers over time if prices are determined on a market rather than cost-of-service basis.

\subsection{Independent NEMS-Based Analysis}

To overcome concerns about the "signal-to-noise" ratio in the Tellus (2002) results, we conducted our own analysis using NEMS. Specifically, we "forced" significant additions - 5, 10, and $15 \mathrm{GW}$ - of wind-power capacity into California, New England, and the Mountain region. The regional multipliers associated with these model runs are shown in Figure 14. Although there is still considerable variation, the results are relatively uniform compared to those from Tellus (2002), and the long term trend in multiplier values over time is as expected. Most of the regional multipliers appear to begin at approximately three and decline to one over time (though not necessarily linearly), perhaps reflecting an assumption that RE additions will initially delay needed regional pipeline expansions but that those expansions will eventually take place and transportation constraints will ease.

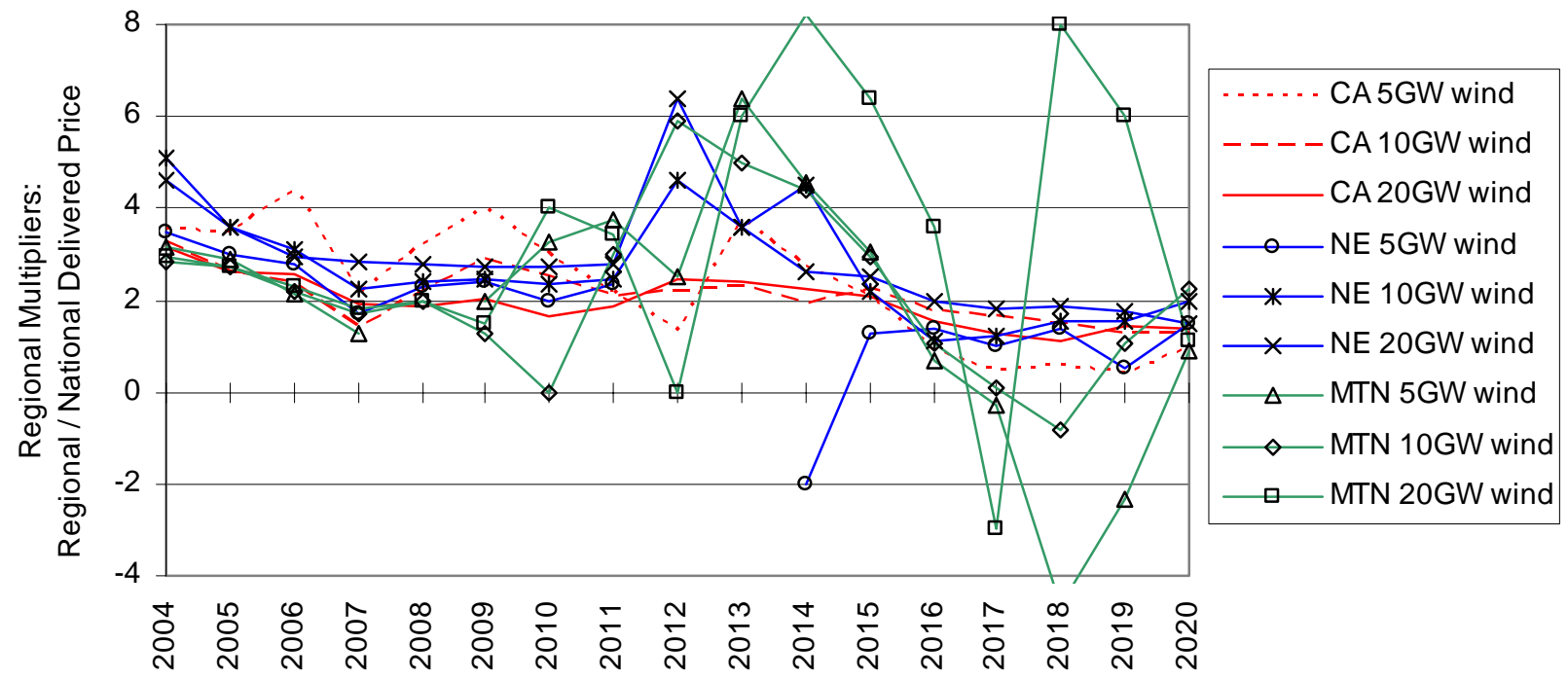

Figure 14. Regional Multipliers for Independent NEMS-Based Analysis

There are, however, no obvious trends in the regional multipliers among regions (i.e., the California multipliers do not appear to be systematically different from the New England and Mountain region multipliers). One would expect those regions with more severe transportation constraints (e.g., New England) to have higher multipliers than those regions without these constraints (e.g., the Mountain region). Such results were derived from the ACEEE study, which found much lower multipliers in Texas than in the other regions analyzed. NEMS does not appear to have the capability to accurately analyze such factors, and this is an area in which further analysis, research, and validation is warranted. 



\section{Benchmarking Against Other Markets and Energy Models}

In evaluating the national results presented in Section 4, it is useful to compare the inverse elasticities implied by the RE/EE deployment studies to those calculated for natural gas and other fossil fuels in other EIA NEMS analyses as well as those from other national energy models.

In particular, the RE and EE studies reviewed above address only one type of exogenous demand shock that triggers a natural gas price response. The low- and high-economic growth scenarios published as part of the EIA's AEO each year are another such example. Low economic growth, compared to the reference case, leads to less demand for fossil fuels, and high economic growth results in the opposite effect. Figure 15 shows the range of average (2003-2020) implied inverse elasticities for natural gas, coal, and oil from AEO 2000-2004, focusing on the low-economicgrowth case relative to the reference-case forecast. ${ }^{37}$

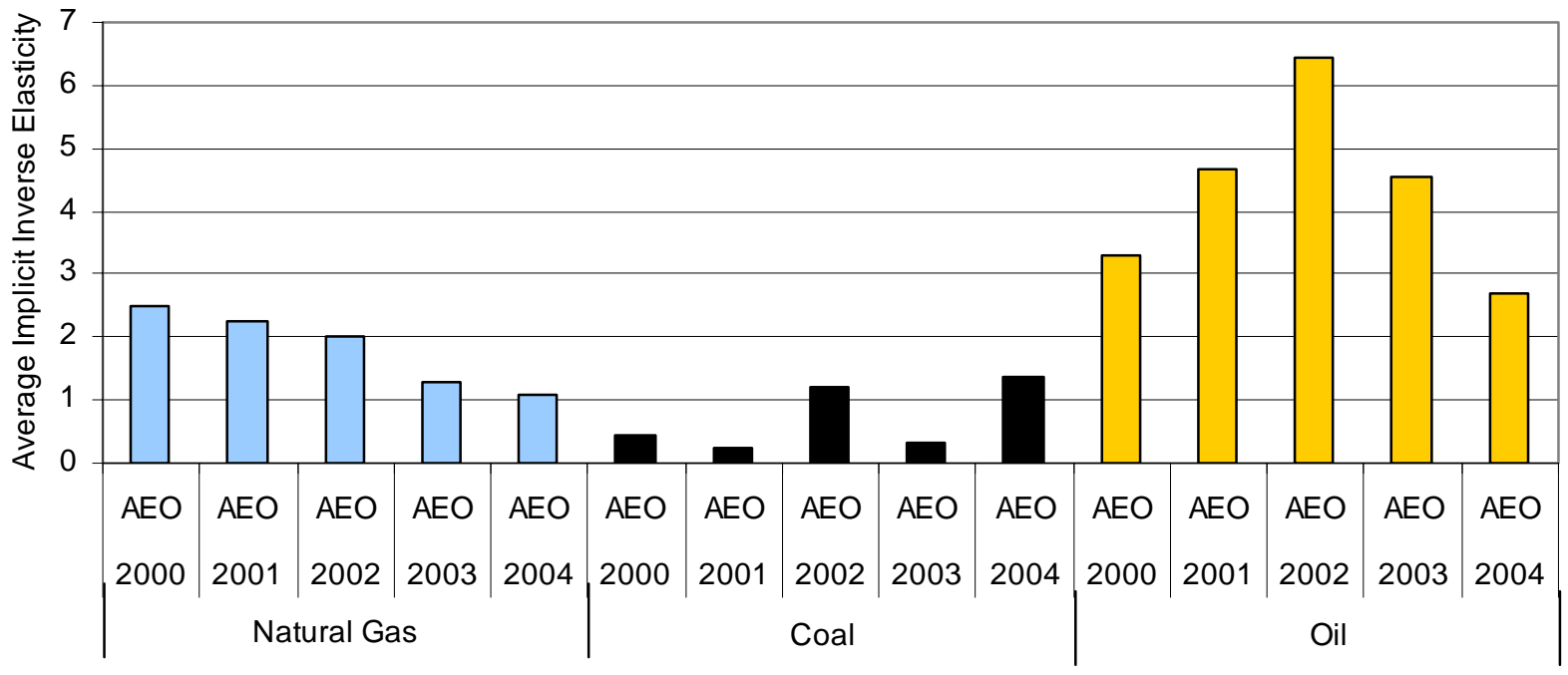

Figure 15. Average Implicit Inverse Price Elasticities for Gas, Coal, and Oil Under the AEO's Low-Economic-Growth Case

The average implicit inverse elasticities for natural gas shown in Figure 15 are broadly consistent with the results of the NEMS-based RE and EE studies presented earlier, i.e., they range from 1.1 to 2.5 , consistent with 14 of 19 of the previously presented analyses. Figure 15 also shows that the implicit inverse elasticities for natural gas appear to have generally decreased with

\footnotetext{
${ }^{37}$ Like the natural gas market, the coal market is assumed to be national, and the implicit inverse elasticity was calculated using forecasts of U.S. coal minemouth prices and total U.S. coal consumption. Oil, on the other hand, is assumed to be a world market, so the elasticity calculation used the world oil price and total world oil consumption from the AEOs.

${ }^{40}$ This may in part result from an assumption of increased imports from outside of the lower-48 states, including substantial increases in the role of imported LNG. Such trade may make natural gas a less national and more worldwide market with prices determined in part by worldwide supply-demand dynamics.
} 
successive versions of NEMS, which the EIA updates each year, perhaps implying that EIA has tried to moderate its treatment of this effect in recent years. ${ }^{40}$ As might be expected given plentiful and relatively inexpensive domestic coal supplies, the implicit inverse elasticity for coal is generally lower than that for natural gas and oil. The inverse elasticity for oil, on the other hand, is much higher than those for coal and gas, reflecting an assumption of highly inelastic supply. ${ }^{41}$

Finding a degree of consistency between the results of the RE and EE studies presented earlier and the AEO's economic-growth cases presented here is not surprising because, with the exception of the ACEEE study, each of these studies used NEMS. We therefore also sought to compare the long-term inverse elasticites implicit in NEMS with those of other national energy models. Data from a recent study by Stanford's Energy Modeling Forum (EMF 2003) allows for this comparison. In particular, the EMF study presents the potential impact of high gas demand on national natural gas consumption and price in 2010 and 2020 using seven different energy models. Table 2 presents the results of this analysis. ${ }^{42}$

\section{Table 2. Implicit Inverse Elasticities in a Range of National Energy Models}

\begin{tabular}{|lcccccc|}
\hline $\begin{array}{l}\text { Energy } \\
\text { Model }\end{array}$ & \multicolumn{2}{c}{$\begin{array}{c}\text { Natural Gas } \\
\text { Consumption Change }\end{array}$} & \multicolumn{2}{c|}{$\begin{array}{c}\text { Natural Gas } \\
\text { Price Change }\end{array}$} & \multicolumn{2}{c|}{$\begin{array}{c}\text { Inverse Price Elasticity } \\
\text { of Supply }\end{array}$} \\
& $\mathbf{2 0 1 0}$ & $\mathbf{2 0 2 0}$ & $\mathbf{2 0 1 0}$ & $\mathbf{2 0 2 0}$ & $\mathbf{2 0 1 0}$ & $\mathbf{2 0 2 0}$ \\
\hline NEMS & $3.0 \%$ & $4.5 \%$ & $6.4 \%$ & $0.5 \%$ & 2.13 & 0.11 \\
\hline POEMS & $4.0 \%$ & $4.3 \%$ & $7.1 \%$ & $7.8 \%$ & 1.75 & 1.81 \\
\hline CRA & $8.7 \%$ & $11.9 \%$ & $20.3 \%$ & $11.1 \%$ & 2.33 & 0.93 \\
\hline NANGAS & $1.2 \%$ & $3.1 \%$ & $7.8 \%$ & $14.8 \%$ & 6.67 & 4.76 \\
\hline E2020 & $4.0 \%$ & $8.4 \%$ & $4.2 \%$ & $6.3 \%$ & 1.03 & 0.76 \\
\hline MARKAL & $3.2 \%$ & $6.3 \%$ & $6.5 \%$ & $13.4 \%$ & 2.04 & 2.13 \\
\hline NARG & $-2.3 \%$ & $-0.2 \%$ & $8.4 \%$ & $9.7 \%$ & -3.57 & -50.00 \\
\hline
\end{tabular}

NEMS (National Energy Modeling System); POEMS (Policy Office Electricity Modeling System), CRA (Charles River Associates), NANGAS (North American Natural Gas Analysis System), E2020 (Energy 2020), MARKAL (MARKet ALlocation), NARG (North American Regional Gas model)

The table shows that inverse elasticity estimates vary substantially among the major national energy models reviewed by the Stanford study. Five of the seven models (NEMS, POEMS, CRA, E2020, and MARKAL) report inverse elasticity estimates that are broadly consistent with those presented earlier, but two of the models (NANGAS and NARG) report anomalous results. Some of these models (e.g., POEMS and MARKAL) rely in part on modeling inputs to NEMS, however, making consistency among the models perhaps less significant than otherwise would be the case. Moreover, the EMF study does not explain the anomalous results for NANGAS and

\footnotetext{
${ }^{41}$ Additional research would need to be conducted to determine whether such a high inverse elasticity is plausible.

${ }^{42}$ The EMF scenarios modeled the impact of increased gas demand on price (an outward shift in the demand curve) whereas we are primarily interested in the impact of decreased gas demand on price (an inward shift in the demand curve). Assuming a smooth supply curve over the long term, however, the elasticities implied by an increase in demand should be essentially equivalent to those implied by a decrease in demand and thus should be comparable to what is addressed in the EE/RE studies described earlier in this paper.
} 
NARG, or why the inverse elasticity for NEMS (and, to a lesser extent, CRA) drops substantially between 2010 and $2020 .^{43}$

The National Petroleum Council (NPC), meanwhile, recently issued a national study relying on the EEA model; the sensitivity cases in that study show an average implicit long-term inverse elasticity (2011-2025) of approximately four (NPC 2003b). This value is consistent with the year 2007 and year 2008 ACEEE results presented earlier in Figure 11, which also relied on the EEA model. Another recent study commissioned by the National Commission on Energy Policy, and using the same EEA model, estimates inverse elasticities that are as high as 16.8 in 2010, dropping to 5.3 in 2020, and then increasing to 7.7 in 2025 (National Commission on Energy Policy 2003). These findings, as well as the earlier ACEEE results, clearly show that the EEA model predicts higher short-term and long-term elasticities than several of the other commonly used national energy models.

\footnotetext{
${ }^{43} \mathrm{We}$ chose not to comprehensively review elasticity estimates provided in earlier models or econometric analyses (see, e.g., Huntington \& Schuler 1990; Pindyck 1974), under the assumption that more recent comparisons would be most relevant. A review of national energy models by Huntington \& Schuler (1990), however, reveals that elasticities implicit in energy models during the late 1980s are consistent with those in the more recent EMF (2003) study; in particular, Huntington \& Schuler (1990) report inverse price elasticities of supply (projected for 2000) that range from 1.1 to 3.3 and are clustered around 1.6 to 2.5 .
} 



\section{Benchmarking Against Empirical Elasticity Estimates}

With few exceptions, the energy-modeling results reviewed previously tell a consistent, basic story: reducing the demand for natural gas, whether through the use of RE and/or EE or other means, is expected to lead to lower natural gas prices than would be the case in a business-asusual scenario. Although the magnitude of the long-term implicit inverse price elasticity of supply varies substantially among models and years, the dominant tendency appears to be values of 0.8 to 2 . That is, a $1 \%$ reduction in national gas demand is expected to cause a corresponding wellhead price reduction of $0.8 \%$ to $2 \%$ in the long-term, with some models predicting even larger effects $(4 \%+$ reductions in long-term gas prices for each $1 \%$ drop in gas consumption).

These are modeling predictions, however, which are based on an estimated shape of a natural gas supply curve that is not known with any precision. It is fair to say that modelers have a dismal track record in accurately estimating future natural gas prices, which raises questions about the degree of confidence we should place in these modeling results. One way to address these questions is to benchmark these forecasts against empirical estimates of historical inverse elasticities. Although empirically derived estimates of historical inverse elasticities will not predict future elasticities accurately (the natural gas supply curve should have a different shape in 2010 than it did in 1990), and data and analysis difficulties plague such estimates, these estimates are nonetheless a dose of empirical reality relative to the modeling results presented earlier.

Unfortunately, empirical research on energy elasticities has focused almost exclusively on the impact of supply shocks on energy demand (demand elasticity) rather than the impact of demand shocks on energy supply (supply elasticity). Our literature search uncovered only one recently published empirical estimate of the long-term supply elasticity for natural gas (limiting our ability to benchmark modeling results with the empirical literature). Krichene (2002) estimates this long-term supply elasticity to be 0.8 (for the period 1973-1999), yielding an inverse elasticity of 1.25. Surprisingly, this is larger than Krichene's short-term inverse elasticity, estimated to be $-10 .^{44}$ Examining the 1918-1973 time period separately, Krichene estimates inverse elasticities of 3.57 in the long term and -1.36 in the short term. Krichene estimates these elasticities using U.S. wellhead prices and international natural gas production, however, making a direct comparison to the model results presented earlier impossible. ${ }^{45}$

With only one published figure (of which we are aware) for long-term natural gas supply elasticity, it may be helpful to review published estimates for other non-renewable-energy commodities, namely oil and coal. Few supply constraints exist for coal, and long-term inverse elasticities are therefore expected to be lower than for natural gas. Oil production, though clearly a worldwide rather than regional market, has more in common with gas, but the Organization of

\footnotetext{
${ }^{44}$ The negative sign on the short-term inverse price elasticity implies that producers will respond to higher prices by reducing production, the opposite of what economic theory would normally expect. To explain this, Krichene (2002) postulates that natural gas production may experience economies of scale and thus a downward sloping short-term supply curve, or alternatively, that producers may recognize the inelastic nature of demand and deliberately restrain output in order to sustain any surge in prices.

${ }^{45}$ One additional study (reported in Dahl \& Duggan 1996) estimates the short-term inverse elasticity of natural gas to range from 6.7 to 37 (Barret 1992).
} 
Petroleum Exporting Countries (OPEC) exerts uncompetitive influences on oil-supply behavior. The comparability of natural gas, oil, and coal elasticities is therefore questionable.

Hogan (1989) estimates short- and long-term inverse elasticities for oil in the U.S. of 11.1 and 1.7, respectively. Looking more broadly at the world oil market, Krichene (2002) calculates the long-term inverse elasticity for oil to be 0.91 from 1918-1973, and 10 from 1973-1999.

Ramcharran (2002) finds evidence of an uncompetitive supply market for oil for the period 1973-1997, with a short-term inverse elasticity estimate of -5.9. For non-OPEC nations, meanwhile, he found a more competitive short-term inverse elasticity of $9.4{ }^{46}$

The EIA (2002b) found only two studies that sought to estimate the supply elasticity for coal. The first, by Beck, Jolly \& Loncar (1991), reportedly estimates an inverse elasticity for the Australian coal industry of 2.5 in the short term and 0.53 in the long term. The second study focuses on the Appalachian region of the U.S. (Harvey 1986) and estimates inverse elasticities of 7.1 in the short term and 3.1 in the long term. ${ }^{47}$

In summary, there are few empirical estimates of supply elasticities against which to benchmark the modeling output described earlier in this paper, and data and analysis problems plague the estimates described above. As important, given changes in the natural gas marketplace, there is no reason to believe that historical elasticity values will be applicable into the future.

Nonetheless, empirical estimates of historical long-term inverse elasticities for gas, coal, and oil are positive, and the modeling output presented earlier for the long-term inverse elasticity of natural gas and other non-renewable-energy commodities (ignoring the shorter-term ACEEE results) is not wildly out of line with historical empirical estimates. Still, the range of implicit long-term inverse elasticities of gas presented earlier is broad, and the empirical literature does not help us narrow that range. In addition, although this view is not clearly supported by either the empirical literature or modeling output, there are some who believe that technological progress is likely to keep the long-term supply curve for natural gas relatively flat, implying a large overstatement of the magnitude of the natural gas price reduction effect in the modeling results presented earlier.

\footnotetext{
${ }^{46}$ A number of additional studies also report short-term supply elasticities for oil (see Dahl \& Duggan 1996).

${ }^{47}$ It may be relevant to report inverse price elasticities for other non-renewable, non-energy commodities. Although we have not systematically researched comprehensive data on these elasticities, Pindyck \& Rubinfeld (1995) report a short-term inverse elasticity of four for copper and a long-term inverse elasticity of 0.67 , while Fisher, Cootner $\&$ Maily (1972) report short- and long-term inverse elasticites of 2.2 and 0.6, respectively, for copper in the U.S.
} 


\section{Developing a Simplified Method}

The subsections below describe our rationale for developing a simple, transparent tool to analyze gas-price impacts, the details of the tool, and its application to RE/EE impacts analysis.

\subsection{Why Develop a Simplified Tool to Analyze Gas-Price Impacts?}

Using integrated national energy models is a resource intensive exercise that often lacks transparency, and many organizations that evaluate RE and EE investments and policies do not have the capability to run these complex models. These organizations instead rely on simpler, more transparent tools that are unable to account for secondary natural gas effects. The method described below can easily be applied to these situations, as we demonstrate through examples.

It is important that our tool be flexible enough to account for uncertainties in the level of impact expected from increased RE and EE investments. Given the unexplained variability in yearly and average inverse elasticity estimates presented earlier in Figures 9-11, along with uncertainty in the fundamental shape of the long-term natural gas supply curve, we do not believe that much weight should be placed on any single result derived from a national energy model. In view of the low "signal-to-noise" ratio associated with modest regional RE and EE additions, it is also possible that results from national energy models would be unreliable for describing the potential impacts of relatively modest state or regional deployment efforts. The simplified approach that we develop here can use a range of plausible inverse elasticity estimates to bound the effect of $\mathrm{RE}$ and $\mathrm{EE}$ on gas prices, and allows the user the flexibility to adopt alternative input assumptions for other variables.

\subsection{Basic Inputs and Assumptions}

Estimating the effect of renewable energy and energy efficiency on gas prices and bills using our tool requires the inputs and assumptions listed in Table 3. 
Table 3. User-Defined Inputs for Simplified Analytic Tool

\begin{tabular}{|c|c|}
\hline Input & Explanation \\
\hline $\begin{array}{l}\text { Level of Increased } \\
\mathrm{RE} \text { and/or EE }\end{array}$ & $\begin{array}{l}\text { Represents the incremental amount of RE/EE in the policy case relative to the business-as- } \\
\text { usual scenario (in MWh). }\end{array}$ \\
\hline $\begin{array}{l}\text { Natural Gas } \\
\text { Displacement Ratio }\end{array}$ & $\begin{array}{l}\text { Represents the share of natural gas generation that is displaced by RE and/or EE. This } \\
\text { displacement may depend on the region in which RE or EE is being deployed and may } \\
\text { change over time as the relative costs of different generation technologies change. As shown } \\
\text { in Appendix A, displacement ratios from the studies evaluated in this paper vary } \\
\text { considerably among studies and over time, averaging between } 34 \% \text { and } 78 \% \text {, with more } \\
\text { recent analyses showing lower levels of gas (and higher levels of coal) displacement. For } \\
\text { national-level analysis, in the absence of better information, we currently recommend an } \\
\text { assumed natural gas displacement ratio of } 40 \% \text {. For regional analysis, a different } \\
\text { displacement ratio may be merited. }\end{array}$ \\
\hline $\begin{array}{l}\text { Natural Gas Heat } \\
\text { Rate }\end{array}$ & $\begin{array}{l}\text { Converts the amount of displaced natural gas generation (in MWh) to an amount of } \\
\text { displaced natural gas consumption (in MMBtu). This variable can be expected to differ with } \\
\text { time and by region. In the near term, increased RE and EE will displace marginal natural gas } \\
\text { plants, which will tend to be older plants with higher heat rates. In the longer term, RE and } \\
\text { EE will displace newer, more-efficient gas plants that would otherwise have been built. } \\
\text { After reviewing results from the EIA's NEMS model (see Appendix A), we recommend the } \\
\text { use of near-term heat rates of } 9,000 \mathrm{Btu} / \mathrm{kWh} \text {. After the first five years of the forecast, heat } \\
\text { rates should drop to approximately } 7,500 \mathrm{Btu} / \mathrm{kWh} \text {. }\end{array}$ \\
\hline $\begin{array}{l}\text { Total Expected } \\
\text { U.S. Natural Gas } \\
\text { Consumption }\end{array}$ & $\begin{array}{l}\text { This variable is required to convert the MMBtu of gas savings estimated by the } \\
\text { multiplication of the above three factors into a percentage reduction in overall U.S. gas } \\
\text { consumption. Estimates of national gas consumption are easily obtained from the latest EIA } \\
\text { Annual Energy Outlook. }\end{array}$ \\
\hline $\begin{array}{l}\text { Inverse Price } \\
\text { Elasticity of } \\
\text { Supply }\end{array}$ & $\begin{array}{l}\text { This variable is used to convert the percentage reduction in U.S. gas consumption into a } \\
\text { percentage reduction in the national average wellhead price. Based on the modeling output } \\
\text { and empirical literature discussed above, this is the most uncertain of the variables included } \\
\text { in the simplified method, and sensitivity analysis using a range of long-term elasticity } \\
\text { estimates is warranted: a range of } 0.8 \text { to } 2 \text {, with a conservative base-case value of } 1.2 \text {, is } \\
\text { recommended here. }\end{array}$ \\
\hline $\begin{array}{l}\text { Business-as-Usual } \\
\text { Wellhead Gas- } \\
\text { Price Forecast }\end{array}$ & $\begin{array}{l}\text { This variable is used to convert the percentage change in wellhead prices calculated above } \\
\text { into \$/MMBtu units. Forecasts of wellhead gas prices are readily obtained from the latest } \\
\text { EIA Annual Energy Outlook. }\end{array}$ \\
\hline $\begin{array}{l}\text { Delivered Price } \\
\text { Conversion }\end{array}$ & $\begin{array}{l}\text { Based on the results presented in Figure } 4 \text {, for national RE/EE analyses, we believe it } \\
\text { reasonable to assume that a } \$ / M M B t u \text { reduction in national wellhead prices will translate } \\
\text { one for one into similar reductions in the national average delivered natural gas price, both } \\
\text { to the electricity sector and to the end-use sectors. }\end{array}$ \\
\hline $\begin{array}{l}\text { Regional } \\
\text { Multipliers }\end{array}$ & $\begin{array}{l}\text { Regional multipliers are used to estimate the differential impacts of regional RE/EE policy } \\
\text { cases. These multipliers will vary by region and with time and should not be used in national } \\
\text { RE/EE policy analyses. As we show in Section 5, NEMS-based state or regional RE/EE } \\
\text { policy cases produce regional multiplier estimates that generally appear to start at } \\
\text { approximately three in the initial year, dropping to one by year } 20 \text {. Though we tentatively } \\
\text { recommend the use of these estimates, especially in transportation-constrained regions, we } \\
\text { note that NEMS-based analysis does not appear able to provide regionally differentiated } \\
\text { multipliers. As a result, we do not have strong confidence in the regional multipliers } \\
\text { recommended here, and believe that further research on the regional impacts of regionally } \\
\text { targeted RE and EE investments is merited. }\end{array}$ \\
\hline
\end{tabular}




\subsection{Applying the Simplified Analysis Tool to RE and EE Deployment Scenarios}

\subsubsection{Scenarios and Scenario-Specific Input Assumptions}

Using the assumptions listed in Table 3, the simplified method can be applied to a range of RE and EE policy and market scenarios. To demonstrate its usefulness, we examine the potential consumer gas savings associated with the following:

Renewable Energy Scenarios

- existing state RPS policies (national impacts),

- California RPS (national and regional impacts),

- New England RPS policies (national and regional),

- New York RPS (national and regional),

- state renewable energy fund support for large-scale (greater than $1 \mathrm{MW}$ ) RE projects to which funds have already been obligated (national),

- $\quad$ projections from the American Wind Energy association of the near-term growth of wind power capacity in the U.S., to 15,000 MW by 2009 (national), ${ }^{48}$ and

- an aggressive Solar Energy Industries Association goal of 36,000 MW of photovoltaics installed in the U.S. by $2020 .^{49}$

Energy Efficiency Scenarios

- California natural gas efficiency savings goal (national and regional), and

- two scenarios of national residential furnace and boiler efficiency standards (national).

In conducting this analysis, we maintain the basic assumptions discussed in Table 3 as a default, including: 1) a 40\% natural gas displacement ratio; 2) heat rates that drop from 9,000 Btu/kWh to 7,500 Btu/kWh; 3) base-case gas consumption and wellhead prices from EIA's AEO 2004; 4) a one-for-one wellhead-to-delivered price conversion; 5) inverse price elasticities of supply of 0.8, 1.2 and 2.0; and, 6) where regional analysis is performed, a regional multiplier of three in the first year, dropping linearly over time to one by year $20 .^{50}$

Additional, scenario-specific assumptions and inputs are described in Text Box 1. The text box notes that, for some of the scenarios, we use natural gas displacement numbers provided by external analysts; in other cases, we use the default assumptions described above, and, in cases where new coal generation is less likely, we assume a higher natural gas displacement ratio than the default $40 \%$. This means that the results provided below are not entirely comparable.

Also, the range of results provided below for each scenario simply reflects differences in the assumed inverse price elasticity of gas supply. The plausible range of impacts is greater than this, given uncertainties in gas displacement and other factors. Although they are not presented here, the simplified analysis tool itself can easily account for these uncertainties.

\footnotetext{
${ }^{48}$ This compares to EIA's AEO 2005 projection of 8,870 MW of wind installed by 2009 .

${ }^{49}$ This compares to EIA's AEO 2005 projection of 320 MW of solar photovoltaics installed by 2020.

${ }^{50}$ Regional multipliers should vary by region, reflecting local gas transportation constraints and the assumed alleviation or worsening of those constraints over time. Absent better regional information, however, here we use the average regional multiplier derived from the NEMS analysis conducted in Section 5. Additional research should be conducted to improve these estimates.
} 


\section{Text Box 1. Data Sources and Scenario-Specific Assumptions}

Existing State RPS Policies: We use UCS estimates of the impact of the 18 existing state RPS policies on new RE development through 2017. By 2017, UCS estimates that these existing standards may support over 100,000 gigawatt hours $(\mathrm{GWh})$ of new RE generation, and we assume that this figure remains constant through 2025 . We further assume a $55 \%$ natural gas displacement ratio, to reflect the fact that much of the RPS-driven demand is likely to occur in California, where a high level of natural gas displacement is likely.

Accelerated California RPS: We rely on CEC data on the projected level of new RE supply needed after 2003 to meet the accelerated statewide RPS target (20\% by 2010 and remaining at $20 \%$ through 2025$)$. By 2010 , nearly $25,000 \mathrm{GWh}$ of new RE supply is projected to come on line. We also assume a 75\% gas displacement ratio, given California's expected continuing reliance on natural gas generation. (http://www.energy.ca.gov/2004_policy_update/documents/2004-0827 workshop/2004-07-30_100-04-003D.PDF).

New England RPS Policies: We use UCS estimates of the impact of the three RPS policies in New England (Massachusetts, Connecticut, and Rhode Island) that are likely to lead to new RE development. By 2017, UCS estimates that these standards could support 9,300 GWh of new RE generation, and we assume that this figure remains constant through 2025. We further assume a 55\% gas displacement ratio, given New England's expected continuing reliance on natural gas generation relative to other parts of the nation.

New York RPS: The NY Public Service Commission (PSC), through its contractors, has evaluated the impacts of New York's RPS. We use gas-displacement figures from that cost study: 7,960,000 MMBtu in 2006, growing to (and staying constant at) 48,105,000 MMBtu in 2013 and thereafter. (http://www3.dps.state.ny.us/pscweb/

WebFileRoom.nsf/Web/85D8CCC6A42DB86F85256F1900533518/\$File/301.03e0188.RPS.pdf?OpenElement).

State Fund Support for RE Projects: This scenario considers the possible impact on gas prices of state renewable energy fund support for large-scale RE projects, only considering projects that are already on line (707 MW) or that have been obligated construction or operational support from state funds (1,550 MW, and assuming that all come on line). (http://eetd.lbl.gov/ea/ems/cases/LBNL-56422.pdf). We assume a 55\% gas displacement ratio, to reflect the fact that much of the SBC-driven demand is expected to occur in California.

American Wind Energy Association (AWEA) Wind Projections: AWEA has estimated that the wind farms already in place and those planned for 2005 will save 0.55 billion cubic feet (Bcf) of natural gas each day (i.e., 204,600,000 MMBtu per year) by 2006; assuming $15,000 \mathrm{MW}$ of wind installed by 2009 , this results in gas savings of $0.9 \mathrm{Bcf} / \mathrm{day}(334,700,000$ MMBtu per year) by the end of the decade. AWEA assumes an aggressive $80 \%$ gas displacement ratio, and a relatively high heat rate (http://www.awea.org/news/news041028mkt.html).

36,000 MW of Solar by 2020: The Solar Energy Industries Association's September 2004 roadmap (http://www.seia.org/media/pdfs/pvroadmap.pdf) sets a goal of 36,000 MW of photovoltaics installed in the U.S. by 2020 (increasing to 200,000 MW by 2030 and 670,000 MW by 2050). We model this goal through 2020 and then assume that capacity remains constant at 36,000 MW through 2025 . We assume a capacity factor of $18 \%$, as well as a gas displacement ratio of $75 \%$ to reflect the fact that solar output is well correlated with peak demand (we could have reasonably assumed a higher heat rate as well, but to be conservative we stuck with our default assumptions).

California Natural Gas Efficiency Goals: The California Public Utilities Commission established, in September 2004, aggressive natural gas savings goals for the state's large investor-owned utilities covering the period 2004-2013 and intended to be captured through natural gas efficiency programs. The cumulative annual savings goals increase from 21 MMTh (2,100,000 MMBtu) in 2004 to 444 MMTh (44,400,000 MMBtu) by 2013 (we assume that savings remain constant after 2013). (http://www.cpuc.ca.gov/word_pdf/AGENDA_DECISION/39963.doc).

National Residential Furnace and Boiler Efficiency Standards: We considered two scenarios based on a potential federal standard for residential heating equipment that uses natural gas. We use data from U.S. DOE as part of its Advance Notice of Proposed Rulemaking for an Energy Conservation Standard for Residential Furnaces and Boilers (http://www.eere.energy.gov/buildings/appliance standards/residential/furnaces boilers.html). Both scenarios use the forecasted gas savings from four product classes from 2012 to 2035: non-weatherized gas furnaces, weatherized gas furnaces, mobile-home gas furnaces, and gas-fired hot-water boilers. Annual fuel utilization efficiency (AFUE) is the measure of the annual operating efficiency of a furnace or boiler. Our Scenario 1 assumes an AFUE of $81 \%$ for nonweatherized gas furnaces, $82 \%$ for weatherized gas furnaces, $80 \%$ for mobile-home gas furnaces, and $84 \%$ for gas-fired water heaters. Our Scenario 2 only differs in its assumption for the AFUE of non-weatherized gas furnaces (which represent $85 \%$ of all product sales), which is set at $92 \%$. Total annual gas savings by 2035 in Scenario 1 equal 0.11 Quads (108,300,000 MMBtu); savings under Scenario 2 rise to 0.38 Quads (376,100,000 MMBtu). 


\subsubsection{Impact on National Average Delivered Gas Prices}

Figure 16 presents the results of our analysis of the impact of the various RE and EE deployment scenarios on the national average delivered gas price in 2025 (with the exception of the furnace and boiler standards, for which the price impact is for year 2035). The scenarios that involve the largest amount of RE and EE deployment, combined with high levels of gas displacement, are those with the largest impacts (reaching delivered gas price reductions as high as over $\$ 0.10 / \mathrm{MMBtu})$. The range of results within each scenario reflects plausible long-term inverse elasticities of 0.8 to 2.0 , with an assumed most likely value of 1.2.

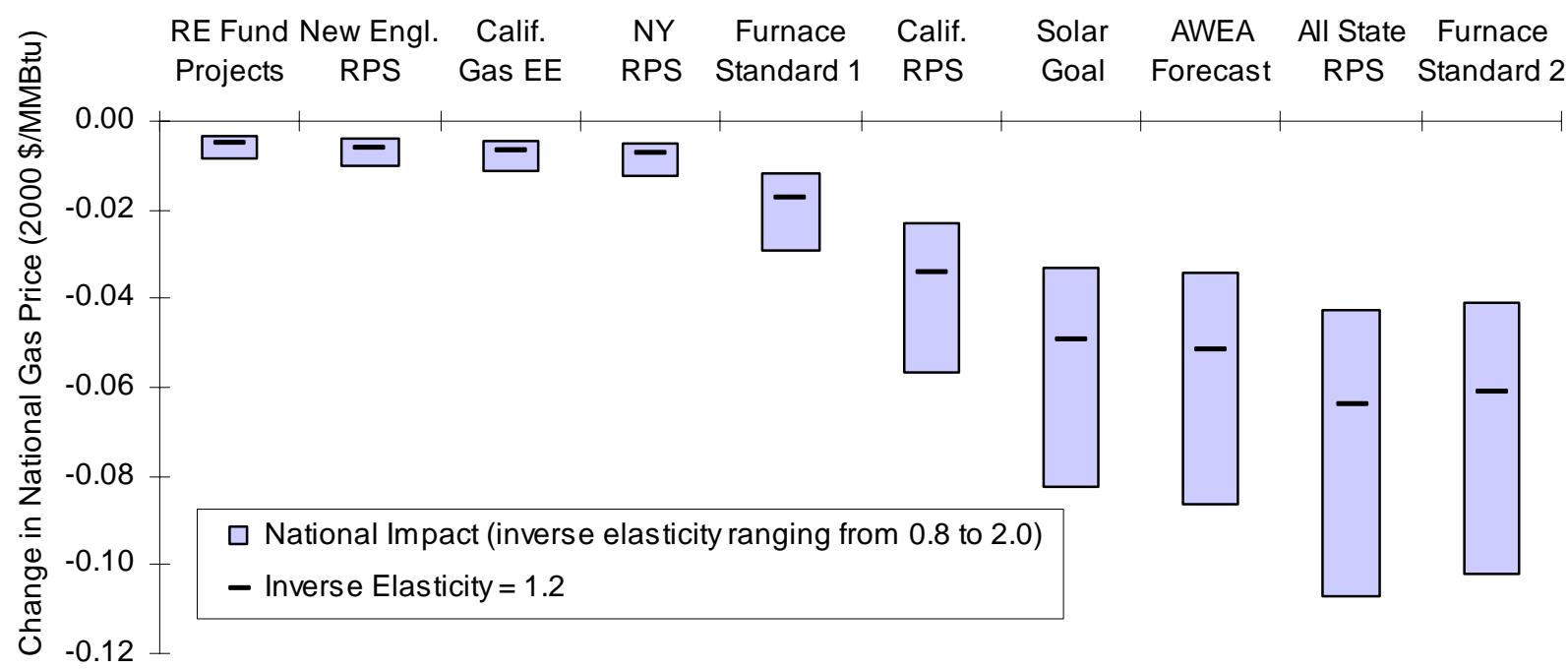

Figure 16. National Gas-Price Impacts Associated with Various RE and EE Scenarios (2025, except furnace standards, which are for 2035)

Given the regional multipliers described earlier, those scenarios involving regionally targeted RE and EE investments have larger regional than national near-term gas-price impacts (not shown in Figure 16). With a multiplier of three in the first year, the regional impact should be three times as large as the national impact. By the end of the forecast period, however, the national and regional impacts on gas prices are equivalent under the assumption that the regional multipliers trend toward one over time.

\subsubsection{Net Present Value of Consumer Gas Savings}

Figure 17 shows the NPV of national consumer gas savings for each of the deployment scenarios. A consistent discount rate of 7\% (real \$) is used, but the NPV time period varies by scenario. $^{51}$

\footnotetext{
${ }^{51}$ Time periods for the net present value (NPV) estimates vary somewhat by scenario, as follows: Colorado RPS (2004-2025), RE Fund Projects (2001-2025), New England RPS (2001-2025), California Gas EE (2004-2025), New York RPS (2004-2025), National Residential Furnace and Boiler Standard 1 (2004-2035), Solar Goal (2004-2025), California RPS (2002-2025), National Residential Furnace and Boiler Standard 2 (2004-2035), All State RPS (20012025), and AWEA Forecast (2004-2025). The 7\% discount rate is used to be consistent with recommendations from the Office of Management and Budget. Note, however, that Awerbuch (2003) and others recommend far lower riskadjusted discount rates, especially for natural gas costs. If such discount rates were used, the NPV of consumer gas savings would be considerably higher than those shown in Figures 17 and 18.
} 


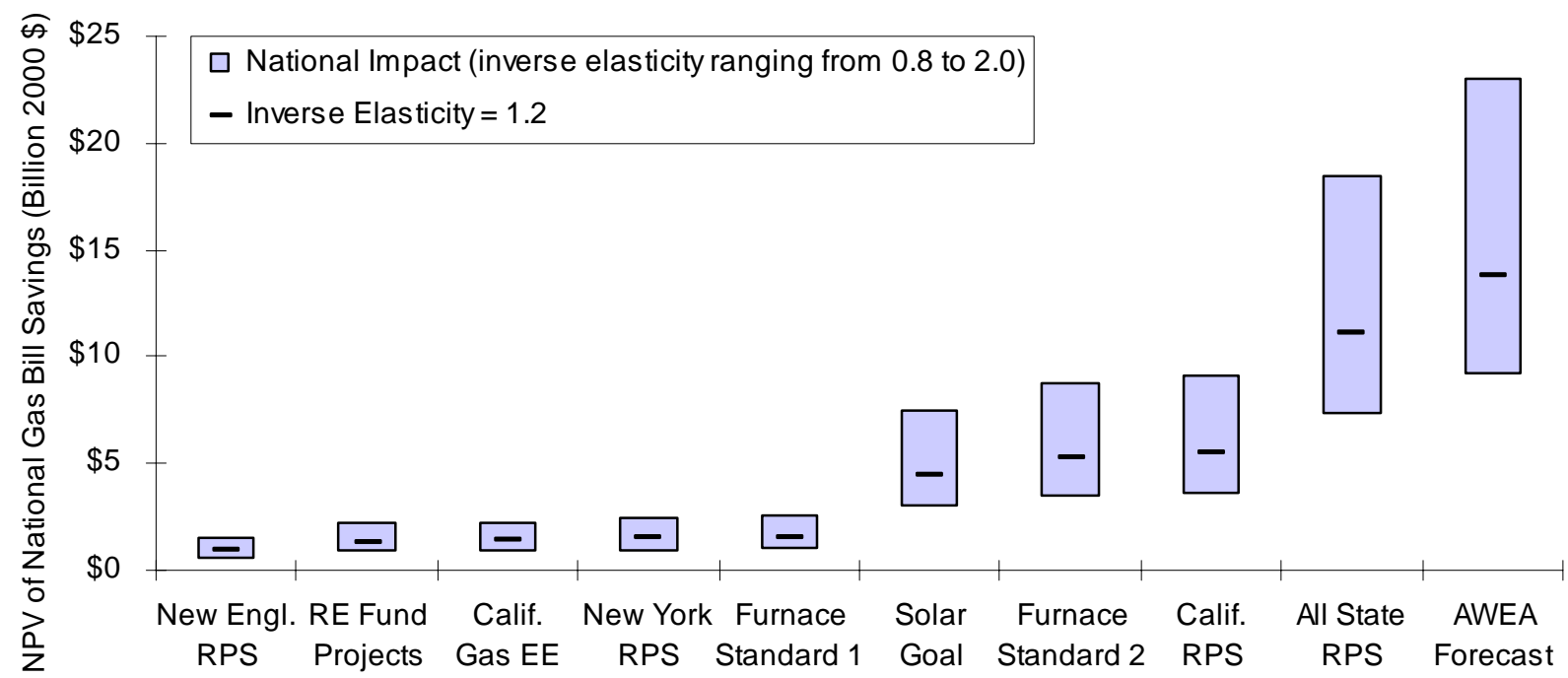

\section{Figure 17. NPV of Consumer Gas Savings (national impacts)}

On a national basis, the NPV of consumer gas savings associated with the scenarios is found to be significant, ranging from a low of $\$ 0.6$ billion to a high of $\$ 23$ billion, depending on the scenario and the particular inverse elasticity that is assumed. As before, the scenarios that involve the largest amount of RE and EE deployment, combined with high levels of gas displacement, are those with the largest impacts. If policymakers are concerned about consumer costs and benefits, these benefits must be weighed against any expected cost of these deployment scenarios.

As shown in Figure 18, the regional bill savings from regionally targeted RE and EE investments are far more modest even though the regional gas price will tend to fall more than the national price (i.e., the regional multiplier is greater than one during most of the forecast period). The relatively modest savings are because the regional gas-price reduction applies to a much lower (i.e., regional instead of national) volume of gas consumption, so the aggregate dollar savings are smaller. Thus, if the effect of RE and EE on consumer gas savings is to play a role in policy debates, it is more likely to play that role in national, rather than state or regional, discussions.

That said, even the lower regional impacts may be significant enough in total dollar terms to affect policy debates. The California RPS, for example, is estimated to provide $\$ 0.7$ to $\$ 1.7$ billion in NPV gas-bill savings to California consumers, while the New York RPS is estimated to provide $\$ 82$ to $\$ 205$ million in savings within New York. 


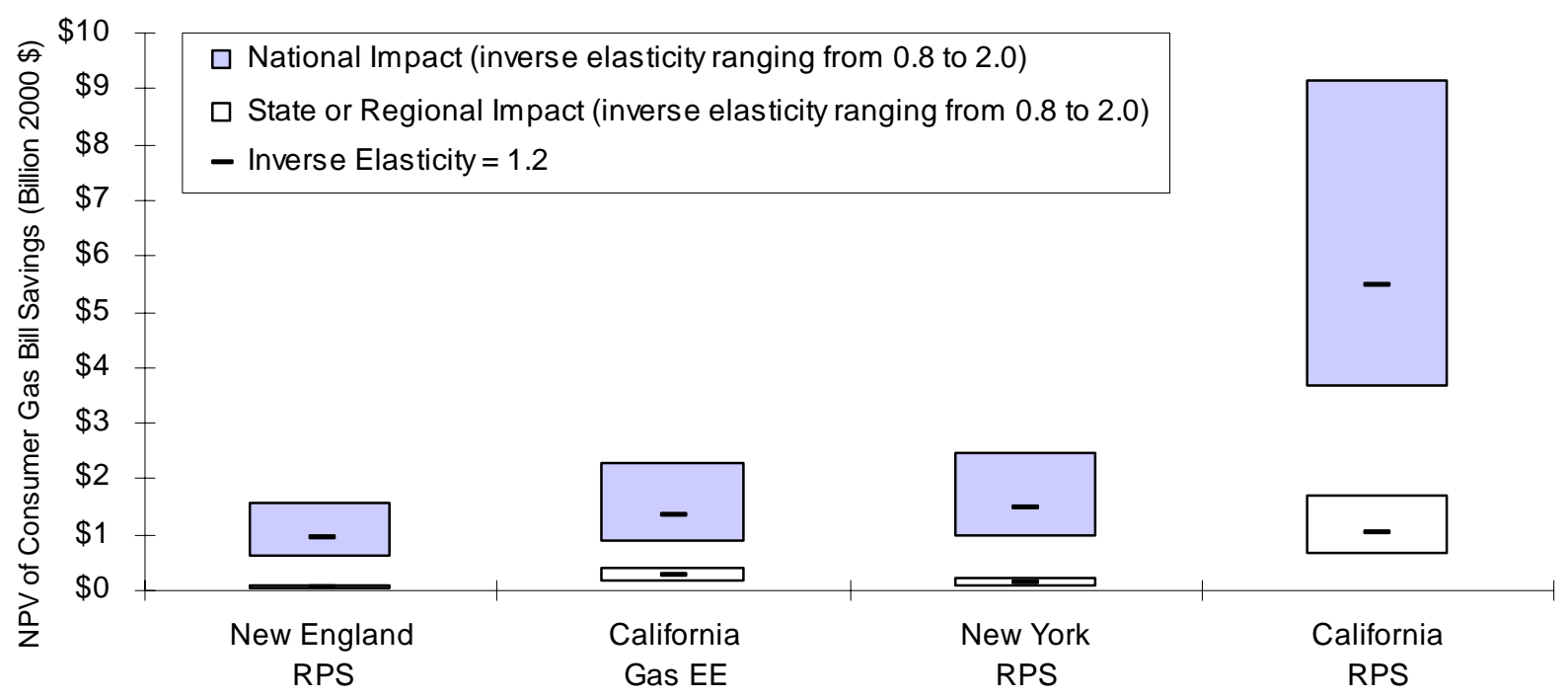

Figure 18. NPV of Consumer Gas Savings (national and regional impacts)

\subsubsection{The Value of RE and EE, in \$/MWh and \$/MMBtu}

Applying the annual consumer gas-bill savings to the incremental amount of RE and/or EE in each scenario, we can estimate the weighted average consumer benefits of increased renewable energy or electricity energy efficiency (in $\$ / \mathrm{MWh}$ ) or gas efficiency measures (in $\$ / \mathrm{MMBtu}$ ). Figure 19 presents the results.

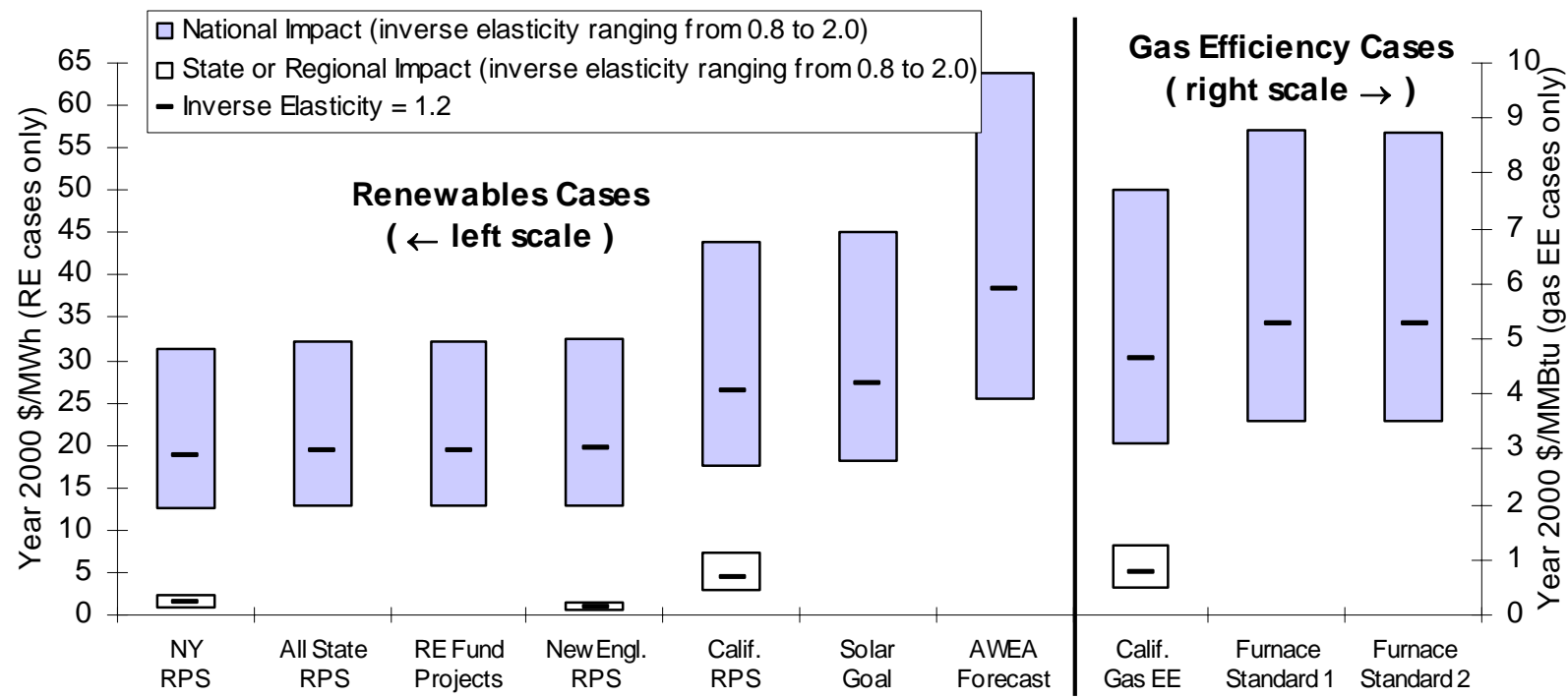

Figure 19. Average Consumer Gas-Savings Benefits of RE and EE (in \$/MWh or \$/MMBtu)

On a national basis, the consumer benefits of RE range from approximately $\$ 10$ per MWh of incremental RE to as high as $\$ 65$ per MWh of incremental renewable energy, depending on the scenario and the inverse elasticity used. The higher figures reflect the highest inverse elasticites 
as well as an assumption of substantial gas displacement for each MWh of renewable energy; a more realistic range might be bounded by $\$ 45 / \mathrm{MWh}$ on the high end. Gas efficiency measures have a national consumer benefit of \$3-\$9 per MMBtu of saved energy.

These results, like those mentioned previously, suggest that the national consumer gas-price benefits from RE and EE may well be substantial. On a regional basis, these per-unit benefits are more modest, with a high of $\sim \$ 5 / \mathrm{MWh}$ under the California RPS scenario, and \$1/MMBtu under the California gas efficiency scenario. Again, this reflects the fact that although the regional gas price will tend to fall more than the national price, this regional gas-price reduction applies to a much lower (i.e., regional instead of national) volume of gas consumption.

\subsection{Calculating the Generic Consumer Value of RE and EE, in \$/MWh}

If we stand back from the specific scenarios analyzed in the previous section, we can use our simplified analysis tool to formulate a generic estimate of the value of RE and EE in reducing national gas bills, in \$-per-MWh-of-renewable-energy terms. This value hinges on three assumptions: 1) the inverse price elasticity of supply, 2) the natural gas displacement ratio, and 3 ) the heat rate of the gas-fired generation being displaced. Of these three variables, the heat rate is least uncertain (see Appendix A); we set it to match the base-case assumptions described earlier (9,000 Btu/kWh through 2007, falling linearly to 7,500 Btu/kWh by 2012 where it stays for the remainder of the forecast period).

Figure 20 shows the national impact of varying the other two parameters: the inverse price elasticity of supply and the displacement ratio. Over the range of likely inverse elasticities identified earlier (i.e., from 0.8 to 2.0 , as denoted by the shaded area), the likely national consumer gas-bill savings of increased RE and EE ranges from about $\$ 5 / \mathrm{MWh}$ (assuming only $20 \%$ gas displacement and an inverse elasticity of 0.8 ) to about $\$ 45 / \mathrm{MWh}$ (assuming $80 \%$ gas displacement and an inverse elasticity of 2.0). These values increase significantly at higher inverse elasticities. Even at the low end of this range, however, the incremental benefits of renewable energy - at $\$ 5$ to $\$ 20$ per MWh of renewable energy - are substantial.

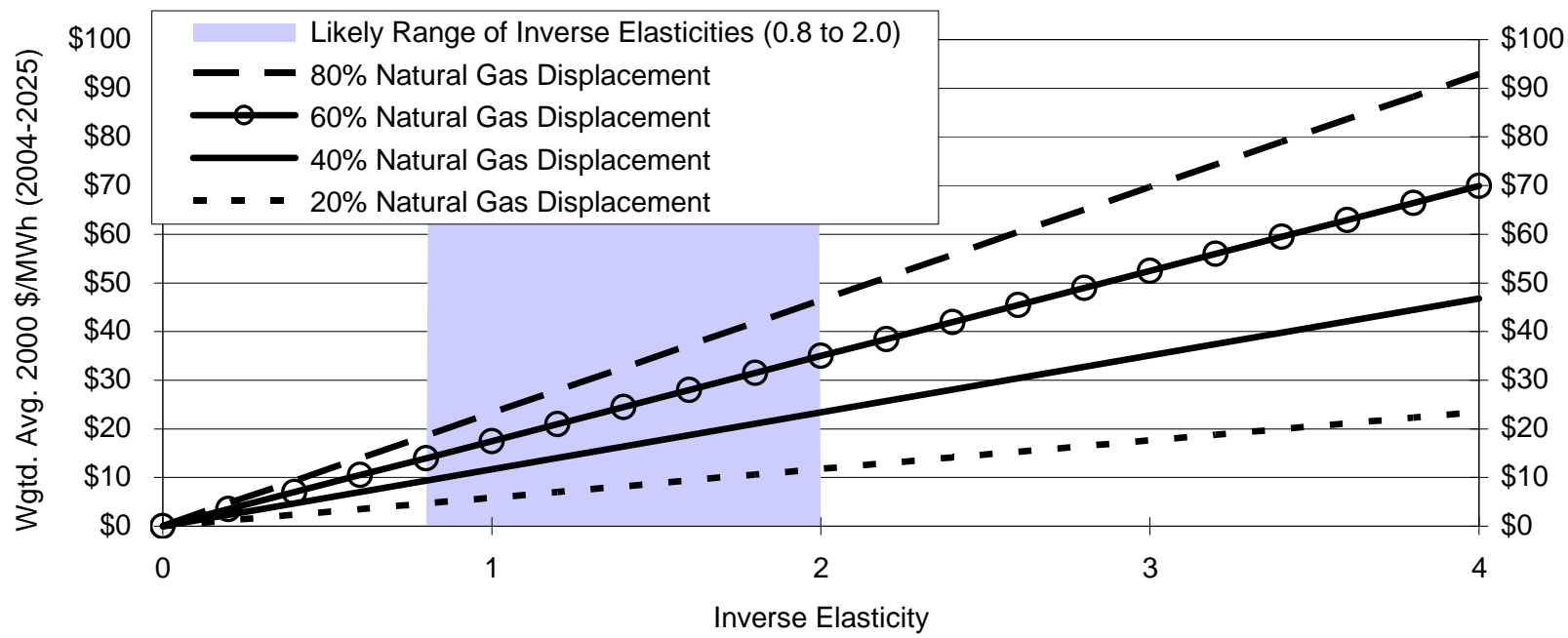

Figure 20. Sensitivity of the \$/MWh Value of RE and EE to Estimates of the Inverse Elasticity and the Gas-Displacement Ratio 


\section{Conclusions}

Concerns about the price and supply of natural gas have grown in recent years, and futures and options markets predict high prices and significant price volatility for the immediate future. Whether we are witnessing the beginning of a major long-term nationwide crisis or a costly but shorter-term supply-demand adjustment remains to be seen.

Results presented in this paper suggest that resource diversification, in particular increased investments in RE and EE, could help alleviate the threat of high natural gas prices over the short and long term. Whether by undertaking gas efficiency measures or by displacing gas-fired electricity generation, increased deployment of $\mathrm{RE}$ and $\mathrm{EE}$ is expected to reduce natural gas demand and consequently put downward pressure on gas prices. A review of the economics literature shows that this effect is to be expected and can be measured with the inverse price elasticity of natural gas supply. Because of the respective shapes of long- and short-term supply curves, the long-term price response is expected to be less significant than the shorter-term response.

The direct effect of this natural gas price reduction may not entirely represent an increase in aggregate economic wealth, and may in part reflect a benefit to natural gas consumers that comes at the expense of natural gas producers. Conventional economics does not generally support government intervention for the sole reason of shifting the demand curve for natural gas and thereby reducing gas prices. If policymakers are uniquely concerned about the impact of gas prices on consumers, however, or are concerned about the potentially harmful macroeconomic impacts of higher gas prices, then policies to reduce gas demand might be considered appropriate; at a minimum, policymakers might view reduced gas prices as a positive secondary effect of increased RE and EE deployment.

A large number of modeling studies have recently been conducted that at least implicitly evaluate this effect. Though these studies show a relatively broad range of inverse price elasticities of natural gas supply (as well as gas displacement ratios), we also find that many of them exhibit some central tendencies. Benchmarking these results against other modeling output as well as a limited survey of the empirical literature, we conclude that many of the studies of the impact of RE and EE on natural gas prices appear to have represented this effect within reason, given current knowledge.

Despite the overall reasonableness of the results observed, there are sometimes significant variations in the implicit inverse elasticities not only among models but also between years within the same modeling run and between runs using the same basic model. Implied inverse elasticities do not always remain within reasonable bounds. Combine this with the fact that the natural gas supply curve is unknown and that the track record of energy modelers predicting future gas prices has not been good, and it is fair to conclude that not much weight should be placed on any single modeling result. More effort needs to be placed on accurately estimating the supply curve for natural gas and on validating models' treatment of that curve before any single modeling result could reasonably be relied upon. 
In the mean time, in estimating the impact of RE and EE on natural gas prices, we strongly recommend scenario analysis: it would be preferable to consider a range of natural gas elasticity estimates (as well as gas displacement ratios) to bound a range of impacts. Relying on the data summarized in this paper, we conclude that each $1 \%$ reduction in national natural gas demand could lead to long-term average wellhead price reductions of $0.8 \%$ to $2 \%$, with some of the models predicting more aggressive reductions. Reductions in the wellhead price will not only have the effect of reducing wholesale and retail electricity rates but will also reduce residential, commercial, and industrial gas bills.

These effects can be readily evaluated using the simplified analysis tool presented in Section 8 . Based on the results presented in this paper, the impact of RE and EE deployment scenarios on delivered gas prices is expected to be significant, resulting in an added consumer value estimated conservatively to be equivalent to $\$ 10-20$ per MWh of RE or EE. 


\section{References}

American Council for an Energy-Efficient Economy (ACEEE). 2003. Natural Gas Price Effects of Energy Efficiency and Renewable Energy Practices and Policies. Report Number E032. Washington, D.C.: American Council for an Energy-Efficient Economy. (Authors: R. Elliot, A. Shipley, S. Nadel, and E. Brown).

Awerbuch, S. 2003. "Determining the Real Cost: Why Renewable Power is More CostCompetitive than Previously Believed." Renewable Energy World, 6 (2).

Bailie, A., S. Bernow, B. Castelli, P. O'Connor, and J. Romm. 2003a. The Path to Carbon Dioxide-Free Power: Switching to Clean Energy in the Utility Sector. Boston, Mass.: Tellus Institute.

Bailie, A., S. Bernow, W. Dougherty, and M. Lazarus. 2003b. Analysis of the Climate Stewardship Act. Boston, Mass.: Tellus Institute.

Barret, C. 1992. "U.S. Natural Gas Market: A Disequilibrium Approach." In Proceedings of the International Association for Energy Economics $15^{\text {th }}$ International Conference, G65-G69. Tours, France: International Association for Energy Economics.

Beck, T., L. Jolly, and T. Loncar. 1991. Supply Response in the Australian Black Coal Industry. Australian Board of Agricultural and Resource Economics, Technical Paper 91.1. Canberra, Australia: Australian Government Publishing Service.

Bernstein, M., P. Holtberg, and D. Ortiz. 2002. Implications and Policy Options of California's Reliance on Natural Gas. Santa Monica, Calif.: RAND.

Bolinger, M., R. Wiser, and W. Golove. 2003. Accounting for Fuel Price Risk: Using Forward Natural Gas Prices Instead of Gas Price Forecasts to Compare Renewable to Natural Gas-Fired Generation. LBNL-53587. Berkeley, Calif.: Lawrence Berkeley National Laboratory.

Brown, S. 2003. U.S. Natural Gas Markets in Turmoil. Testimony prepared for a hearing on The Scientific Inventory of Oil and Gas Resources on Federal Lands, U.S. House of Representatives. 19 June.

California Energy Commission (CEC). 2003. Natural Gas Market Assessment. 100-03-06. Sacramento, Calif.: California Energy Commission.

Center for Clean Air Policy (CCAP). 2003. Recommendations to Governor Pataki for Reducing New York State Greenhouse Gas Emissions. Washington, D.C.: Center for Clear Air Policy.

Dahl, C., and T. Duggan. 1996. "U.S. Energy Product Supply Elasticities: A Survey and Application to the U.S. Oil Market." Resources and Energy Economics 18: 243-263.

Dahl, C., and T. Duggan. 1998. "Survey of Price Elasticities from Economic Exploration Models of US Oil and Gas Supply.” Journal of Energy Finance and Development 3 (2): 129-169. 
Energy and Environmental Analysis, Inc. (EEA). 2004. Natural Gas Issues for the U.S. Industrial and Power Generation Sectors. Prepared for the National Commission on Energy Policy. Arlington, Virginia: Energy and Environmental Analysis, Inc.

Energy Information Administration (EIA). 1998. Analysis of S. 687, the Electric System Public Benefits Protection Act of 1997. SR/OIAF/98-01. Washington D.C.: Energy Information Administration.

Energy Information Administration (EIA). 1999. Annual Energy Outlook 2000. DOE/EIA-0383 (2000). Washington D.C.: Energy Information Administration.

Energy Information Administration (EIA). 2001. Analysis of Strategies for Reducing Multiple Emissions from Electric Power Plants: Sulfur Dioxide, Nitrogen Oxides, Carbon Dioxide, and Mercury and a Renewable Portfolio Standard. SR/OIAF/2001-03. Washington D.C.: Energy Information Administration.

Energy Information Administration (EIA). 2002a. Impacts of a 10-Percent Renewable Portfolio Standard. SR/OIAF/2002-03. Washington D.C.: Energy Information Administration.

Energy Information Administration (EIA). 2002b. Model Documentation Coal Market Module of the National Energy Modeling System. DOE/EIA-M060 (2002). Washington, D.C.: Energy Information Administration.

Energy Information Administration (EIA). 2003. Analysis of a 10-Percent Renewable Portfolio Standard. SR/OIAF/2003-01. Washington D.C.: Energy Information Administration.

Energy Innovations. 1997. Energy Innovations: A Prosperous Path to a Clean Environment. Washington, DC: Alliance to Save Energy, American Council for an Energy-Efficient Economy, Natural Resources Defense Council, Tellus Institute, and Union of Concerned Scientists.

Energy Modeling Forum (EMF). 2003. Natural Gas, Fuel Diversity and North American Energy Markets. EMF Report 20, Volume I. Stanford, Calif.: Stanford University.

Fisher, F., P. Cootner, and M. Maily. 1972. "An Econometric Model of the World Copper Industry." The Bell Journal of Economics and Management Science 3 (2): 568-609.

Harvey, C. 1986. Coal in Appalachia: An Economic Analysis. Lexington, Ky.: University Press of Kentucky.

Henning, B., M. Sloan, and M. de Leon. 2003. Natural Gas and Energy Price Volatility. Arlington, Virginia: Energy and Environmental Analysis, Inc.

Hogan, W. 1989. World Oil Price Projections: A Sensitivity Analysis. Prepared pursuant to the Harvard-Japan World Oil Market Study, Energy Environmental Policy Center, John F. Kennedy School of Government. Cambridge, Mass.: Harvard University.

Holtberg, P. 2002. "Can We Have a Bright Natural Gas Future with Near-Term Uncertainty?" The Journal of Energy and Development 26 (2): 283-300. 
Huntington, H., and G. Schuler. 1990. "North American Natural Gas Markets: Summary of an Energy Modeling Forum Study." The Energy Journal 11 (2): 1-20.

ICF Consulting (ICF). 2003. Report of Initial Analysis of Proposed New York RPS. Fairfax, Va.: ICF Consulting.

Interlaboratory Working Group. 2000. Scenarios for a Clean Energy Future. LBNL-44029. Berkeley. Calif.: Lawrence Berkeley National Laboratory.

Krichene, N. 2002. "World Crude Oil and Natural Gas: A Demand and Supply Model.” Energy Economics 24: 557-576.

National Association of Regulatory Utility Commissioners (NARUC). 2003. Natural Gas Information “Toolkit.” Washington, D.C.: National Association of Regulatory Utility Commissioners.

National Commission on Energy Policy. 2003. Increasing U.S. Natural Gas Supplies: A Discussion Paper and Recommendations from the National Commission on Energy Policy. Washington, D.C.: National Commission on Energy Policy.

National Petroleum Council (NPC). 2003a. Balancing Natural Gas Policy - Fueling the Demands of a Growing Economy. Volume I, Summary of Findings and Recommendations. Washington, D.C.: National Petroleum Council.

National Petroleum Council (NPC). 2003b. Balancing Natural Gas Policy - Fueling the Demands of a Growing Economy. Volume II: Integrated Report. Washington, D.C.: National Petroleum Council.

Palmer, K. and D. Burtraw. 2004. Electricity, Renewables, and Climate Change: Searching for a Cost-Effective Policy. Resources for the Future.

Parry, I., and J. Darmstadler. 2003. The Costs of U.S. Oil Dependency. Discussion Paper 03-59. Washington, D.C.: Resources for the Future.

Pindyck, R. 1974. "The Regulatory Implications of Three Alternative Econometric Supply Models of Natural Gas.” The Bell Journal of Economics and Management Science 5 (2):633645.

Pindyck, R., and D. Rubinfeld. 1995. Microeconomics. Englewood Cliffs, N.J.: Prentice Hall Publishers.

Ramcharran, H. 2002. "Oil Production Responses to Price Changes: An Empirical Application of the Competitive Model to OPEC and non-OPEC Countries.” Energy Economics 24: 97-106.

Tellus. 2002. Modeling Analysis: Renewable Portfolio Standards for the Rhode Island GHG Action Plan. Boston, Mass.: Tellus Institute. (Authors: S. Bernow and A. Bailie). 
Union of Concerned Scientists (UCS). 1999. Powerful Solutions: 7 Ways to Switch America to Renewable Energy. Cambridge, Mass.: Union of Concerned Scientists. (Authors: A. Nogee, S. Clemmer, B. Paulos and B. Haddad).

Union of Concerned Scientists (UCS). 2001. Clean Energy Blueprint: A Smarter National Energy Policy for Today and the Future. Cambridge, Mass.: Union of Concerned Scientists. (Authors: S. Clemmer, D. Donovan, A. Nogee and J. Deyette).

Union of Concerned Scientists (UCS). 2002a. Renewing Where We Live. February 2002 edition. Cambridge, Mass.: Union of Concerned Scientists.

Union of Concerned Scientists (UCS). 2002b. Renewing Where We Live. September 2002 edition. Cambridge, Mass.: Union of Concerned Scientists.

Union of Concerned Scientists (UCS). 2003. Renewing Where We Live. September 2003 edition. Cambridge, Mass.: Union of Concerned Scientists.

Union of Concerned Scientists (UCS). 2004a. Renewable Energy Can Help Ease the Natural Gas Crunch. Cambridge, Mass.: Union of Concerned Scientists.

Union of Concerned Scientists (UCS). 2004b. Renewing America's Economy: A 20 Percent National Renewable Energy Standard Will Create Jobs and Save Consumers Money. Cambridge, Mass.: Union of Concerned Scientists.

Union of Concerned Scientists (UCS). 2004c. The Colorado Renewable Energy Standard Ballot Initiative: Impacts on Jobs and the Economy. Cambridge, Mass.: Union of Concerned Scientists. (Authors: J. Deyette and S. Clemmer). 


\section{Appendix A. Impact of Incremental Renewable Energy Generation on Natural Gas Generation Displacement and Heat Rates}

Focusing on the studies that evaluate the impact of national RPS policies, Figures A-1, A-2, and A-3 report the natural gas displacement ratios and implicit heat rates of displaced gas-fired generation.

Figure A-1 shows that natural gas displacement ratios - defined as the percent of incremental renewable energy generation that displaces gas-fired generation - vary considerably among studies and over time.

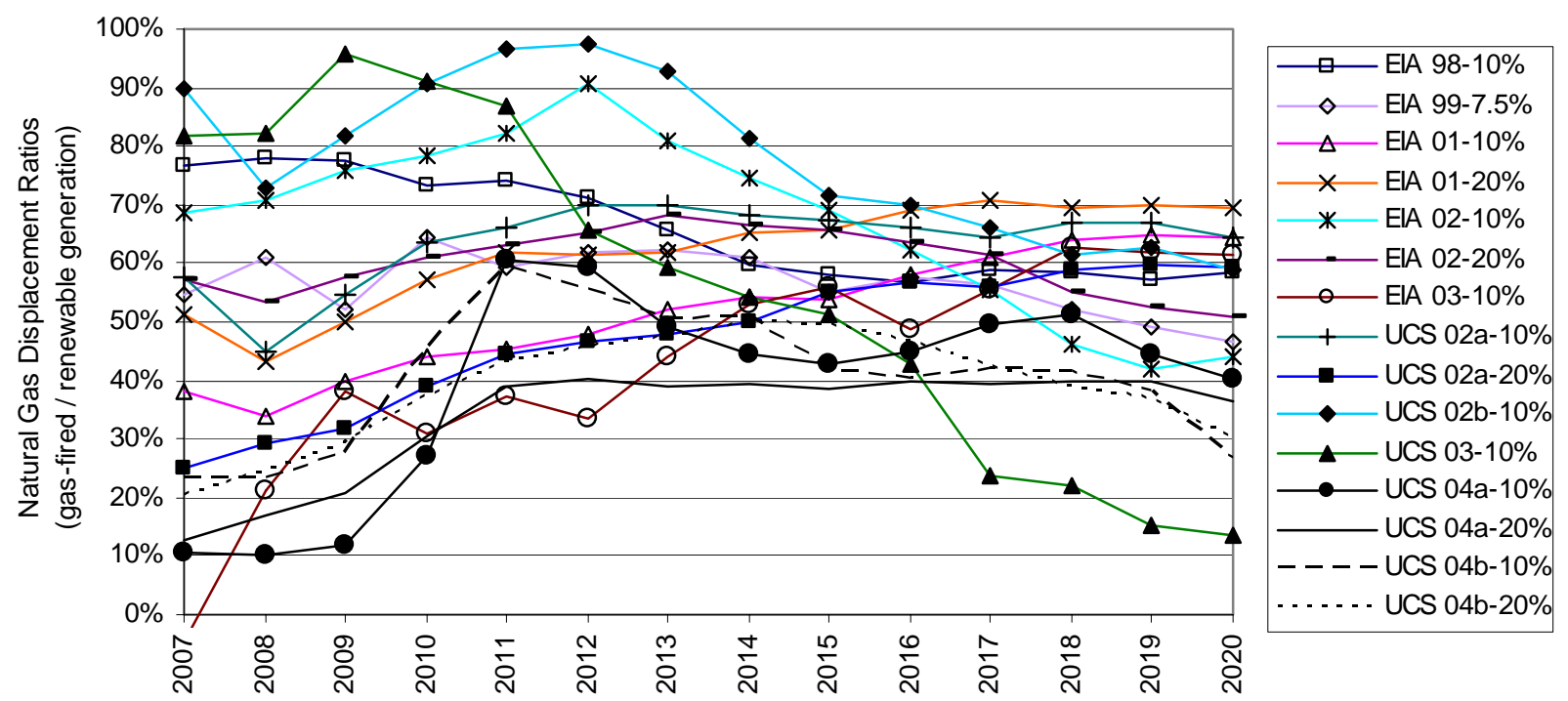

Figure A-1. Annual Natural Gas Displacement Ratios, by Study

Though it masks yearly changes, Figure A-2 reports the average displacement ratio, by study, and shows that the most recent RPS analyses (UCS 2004a and 2004b) generally have lower gasdisplacement ratios, presumably because the higher expected price of natural gas in the later analyses leads to greater coal generation additions, and therefore coal displacement. The displacement ratios in UCS (2004a and 2004b) suggest that every incremental MWh of renewable generation displaces 0.3-0.4 MWh of natural-gas-fired generation (displacement ratios of $30-40 \%$ ). Earlier studies' average displacement ratios generally range from $45 \%$ to $75 \%$.

Figure A-3 shows the implicit heat rate of displaced gas-fired generation. Although there is variation, implicit heat rates in the early years appear to average $\sim 9,000 \mathrm{Btu} / \mathrm{kWh}$, declining to $\sim 7,500 \mathrm{Btu} / \mathrm{kWh}$ over time and then remaining largely constant at that level. 


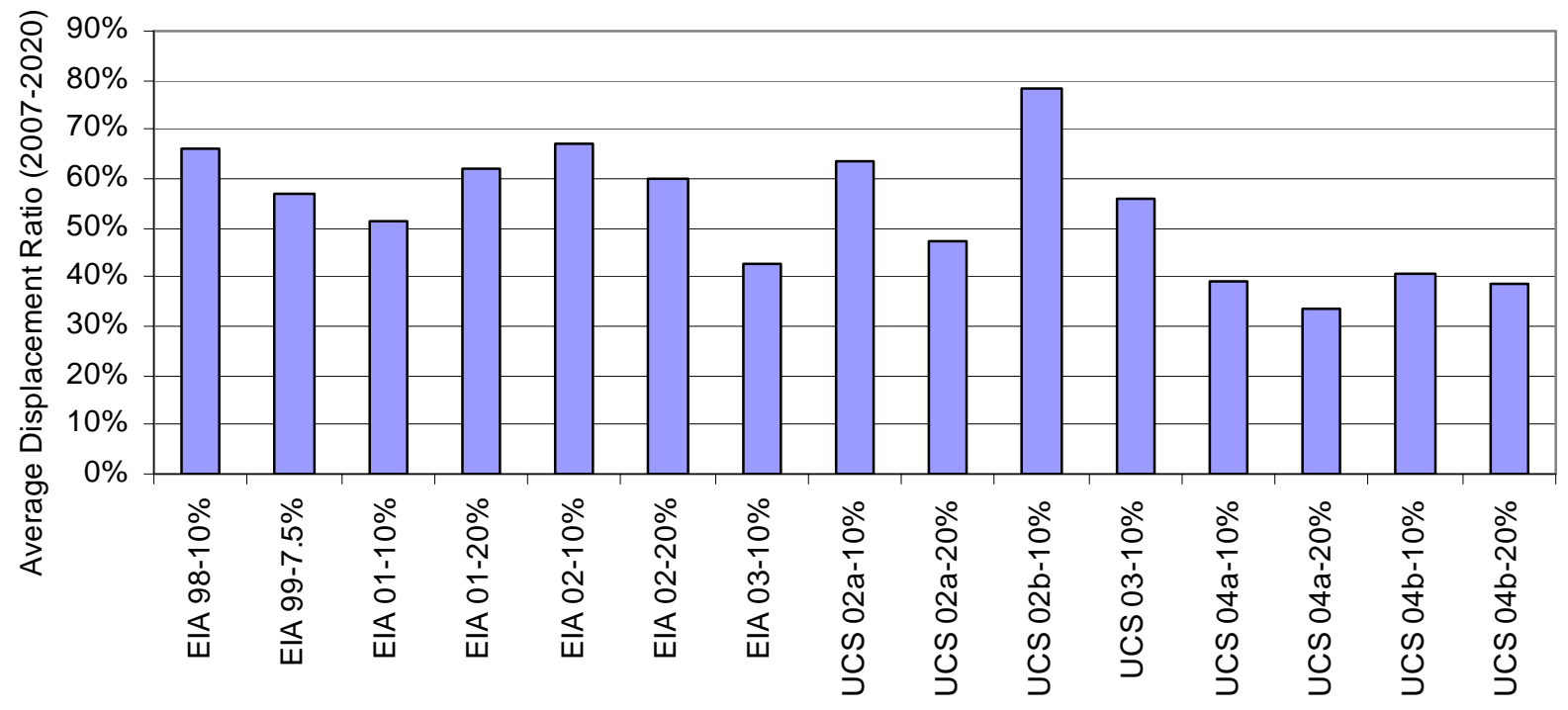

Figure A-2. Average Natural Gas Displacement Ratios, by Study
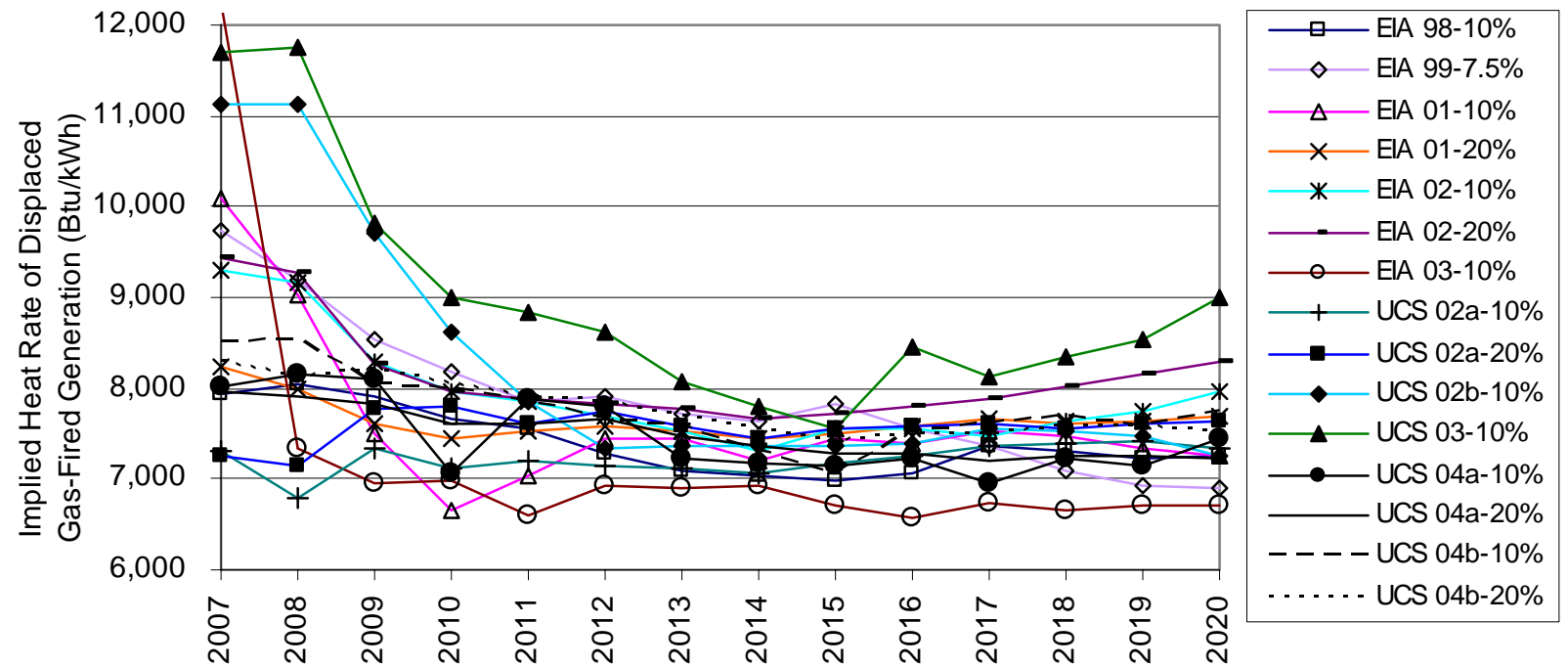

Figure A-3. Annual Natural Gas Heat Rates, by Study 